\title{
Cuando lo local no es función de lo nacional. Efectos DIFERENCIALES DEL CAMBIO INSTITUCIONAL EN COLOMBIA (1997-2015)
}

\author{
When Local Politics Does Not Follow National Trends: Differential \\ Effects of Institutional Change in Colombia (1997-2015)
}

\author{
JUAN ALBARRACÍN \\ Universidad Icesi, Cali, Colombia
}

JUAN PABLO MILANESE

Universidad Icesi, Cali, Colombia

\begin{abstract}
RESUMEN
Utilizando una estrategia multi método, el artículo muestra que los cambios en las reglas electorales implementados en Colombia en 2003 tuvieron un efecto contrario al esperado en las elecciones para los concejos municipales: aumentó la fragmentación del sistema de partidos y la intensidad de la competencia personalista. Adicionalmente, pese a que en el caso de la competencia personalista se produjo un efecto homogeneizador de municipios de diferentes tamaños, se volvieron más heterogéneos en cuanto a la fragmentación partidaria. Sin embargo, la mayor fragmentación promedio no necesariamente refleja una más alta competencia entre partidos en todos los municipios. El uso de múltiples etiquetas partidarias, y el consiguiente aumento en la fragmentación, también puede ser una estrategia por parte de máquinas políticas hegemónicas para controlar más escaños en el nuevo contexto institucional. Finalmente, el artículo no solo nos permite apreciar los límites de la ingeniería institucional pensada "desde el centro" hacia unidades subnacionales, ya que revela, además, cómo el empleo de múltiples métodos con un diseño de investigación subnacional (SNR) posibilita el desarrollo descripciones más robustas de procesos políticos locales, evitando así potenciales interpretaciones parciales derivadas del empleo de un solo método.
\end{abstract}

Palabras clave: reformas electorales, Colombia, elecciones locales, investigación subnacional, fragmentación del sistema de partidos, competencia personalista intrapartidaria.

\begin{abstract}
This article uses a multimethod research strategy to show that changes in electoral rules implemented in Colombia in 2003 did not have the expected effects in municipal council elections: party system fragmentation and personalistic intra-party competition increased. Moreover, while the effect of reform was more homogenous across municipalities with regard to intra-party competition, it was more heterogenous across these units with respect to party system fragmentation. Moreover, a higher average level of party system fragmentation does not necessarily reflect greater competition between parties in all municipalities. The use of multiple party labels and the ensuing increase in fragmentation can also be a strategy by hegemonic machines to control a greater number of seats in the new institutional context. In this way, this article does not only reveal the limits of institutional
\end{abstract}


engineering mandated from the national level. It also shows how multimethod strategies in the context of a subnational research design (SNR) can provide more robust descriptions of local political processes, thus avoiding potentially partial interpretations derived from single-method designs.

Keywords: electoral reform, intra-party personalistic competition, party system fragmentation, Colombia, subnational research, local elections.

\section{INTRODUCCIÓN ${ }^{1}$}

A finales de los años noventa ocurrió un cambio dramático en el sistema de partidos colombiano. Después de más de un siglo de preponderancia, el progresivo debilitamiento de los Partidos Liberal (PLC) y Conservador (PCC) produjo altos niveles de fragmentación y volatilidad electoral. La elección de un presidente disidente sobre el candidato oficial del PLC en 2002 fue visto como el punto de quiebre en este proceso (Albarracín et al. 2018). Esta creciente debilidad de los partidos "tradicionales" en la arena electoral y legislativa nacional, así como la consecuente transformación del sistema de partidos, fue asociada al cambio de las reglas electorales y, no sorprendentemente, se intentó "contener" el proceso de fragmentación y el aumento de la competencia personalista por medio de reformas institucionales en 2003 (Shugart et al. 2007; Botero y Rodríguez Raga 2008).

Si bien el diagnóstico era correcto y las reformas lograron contener la fragmentación del sistema en el ámbito nacional, los procesos partidarios y electorales a nivel subnacional no mostraron los mismos patrones. Allí, los partidos tradicionales continuaban siendo las fuerzas predominantes de muchas regiones y municipios (Gamboa 2012), y la fragmentación del sistema estaba contenida. Evidentemente, la política electoral subnacional colombiana, en particular después de los procesos de descentralización en los años ochenta y noventa, había dejado de ser un reflejo de la nacional. Esto no fue tenido en cuenta a la hora de realizar cambios institucionales que aplicaron para todos los niveles, ignorando los potenciales efectos que estos podían tener sobre la arena regional y local o, simplemente, asumiendo que estos serían homogéneos en todos los ámbitos involucrados.

El artículo muestra que, contrario a las expectativas, los cambios institucionales están asociados a un aumento de la fragmentación del sistema de partidos y de la intensidad de la competencia personalista en las elecciones para los concejos municipales (1997-2015). ${ }^{2}$ De igual manera, se presenta evidencia de que los efectos de las variables institucionales cambian de acuerdo con el municipio.

Agradecemos a Laura Gamboa y a las/los evaluadores/as anónimos/as por sus excelentes comentarios y sugerencias. Cualquier error u omisión es nuestra responsabilidad.

2 El estudio no incluyó a las elecciones de 2019 por no ser todavía públicos los resultados con el nivel de desagregación necesario. 
Mientras que en el caso de la competencia personalista se produjo un efecto homogeneizador de distritos electorales de diferentes tamaños, en el caso de la fragmentación del sistema partidario se incrementó la heterogeneidad entre estos.

Además, se muestra cómo al asumir que los resultados de las nuevas instituciones serían relativamente uniformes en el nivel subnacional, se ignoró la agencia de los políticos locales y regionales para responder a los nuevos incentivos institucionales. Estas respuestas no coincidirían, necesariamente, con las expectativas tanto de la teoría institucional como de los "reformadores" colombianos. En particular, mostramos con la comparación de dos casos cómo la tendencia a una mayor fragmentación del sistema de partidos observada en los municipios no siempre implica un mayor nivel de competencia entre fuerzas políticas.

Se llega a estas conclusiones utilizando un diseño de investigación subnacional (SNR, por su sigla en inglés). Como resaltan Giraudy, Moncada y Snyder (2019), estos permiten identificar los límites de teorías pensadas para explicar procesos de nivel nacional en ámbitos subnacionales, evitando tanto el theory stretching como la aplicación irreflexiva de teorías sin considerar el ámbito para el que fueron pensadas.

Adicionalmente, los diseños subnacionales permiten realizar estudios que combinan métodos de forma creativa (Giraudy et al. 2019) porque posibilitan el incremento del número de casos y el hacer uso de métodos cuantitativos para poder establecer descripciones generales. En este sentido, se realiza un análisis del impacto que tuvo la Reforma Política de 2003 sobre las elecciones de concejos municipales que permitió identificar los cambios que, en promedio, se produjeron como consecuencia de dicha reforma. Dado que la política municipal no es geográficamente homogénea y existe la posibilidad de que haya patrones regionales (Harbers y Ingram 2019), especialmente en un país como Colombia, caracterizado por visibles divergencias de este tipo, se utilizaron modelos espaciales para identificar los efectos diferenciales de la reforma en cada municipio.

Por último, aprovechamos la ventaja de los estudios subnacionales para comparar cualitativamente casos con niveles de semejanza difícilmente alcanzados en comparaciones cross-national (Snyder 2001). Se contrasta a los municipios de Cali y Palmira para ilustrar cómo los actores políticos locales reaccionaron de forma diferente a las nuevas reglas electorales. Aunque en ambos se observan contextos institucionales muy similares y nominalmente se llega al mismo resultado, los procesos en cada municipio son visiblemente distintos. De este modo, el empleo de múltiples métodos con un SNR nos permite desarrollar descripciones más robustas de procesos políticos subnacionales y evitar interpretaciones parciales derivadas del uso de un solo método.

El artículo contribuye a la rica y creciente bibliografía de estudios subnacionales en América Latina (Suarez-Cao et al. 2017). En particular, los resultados aquí presentados están en línea con estudios previos de regiones y municipios 
colombianos que han mostrado que, en lo referido a las elecciones, la política subnacional no es el espejo de la nacional (García 2006; Bedoya y Arenas 2015; Milanese y Jaramillo 2015; Abadía 2016; Batlle et al. 2020; Pino 2020). Sin embargo, el diseño de investigación permite encontrar sistematicidad en los resultados, mostrando que los patrones disonantes entre niveles no son, en realidad, un producto de la atipicidad de casos específicos.

\section{VARIABLES INSTITUCIONALES Y COMPETENCIA ELECTORAL}

Los estudios sobre los efectos de las instituciones políticas suelen basarse en la premisa de que estas deben impactar, de forma homogénea, el comportamiento de los actores independientemente del contexto. De la misma manera, cuando se llevan a cabo procesos de reforma electoral, se asume que las instituciones producirán resultados similares sin importar el país o el nivel en el que se implementan. La Reforma Política de 2003 en Colombia no fue la excepción. Su diseño pretendía contener a un sistema de partidos que se fragmentaba rápidamente y en el que estos habían perdido su capacidad de regular la competencia electoral (Botero y Rodríguez Raga 2008).

Así, buscando generar incentivos que redujeran la fragmentación del sistema y su nivel de personalización, se alteraron, sobre todo, las reglas de agregación de votos con el tipo de listas y las fórmulas de distribución de escaños. No obstante, la realidad superó la expectativa de los reformadores, produciendo resultados heterogéneos de acuerdo con el ámbito de la elección (nacional-subnacional). A continuación, se describen las expectativas teóricas sobre estas y otras variables de los sistemas electorales, para después formular hipótesis asociadas a los efectos esperados de la reforma dadas las nuevas reglas impuestas desde el nivel nacional.

\section{Agregación de votos y tipo de listas}

El modo en que se estructura formalmente el voto influye en el tipo de competencia electoral, de hecho, se espera que en aquellos casos donde los votantes cuentan con mayor capacidad para expresar preferencias por los candidatos presentes en las listas, se incremente la tensión dentro de ellas (Carey y Shugart 1995), haciendo que exista no solamente competencia entre partidos, sino también dentro de ellos (Katz 1986).

Dentro de este marco, elementos como los modelos de ordenamiento de las listas, el control de los líderes sobre su conformación y el tipo de agregación de los votos (pooling) inciden en el comportamiento de los candidatos, favoreciendo la adquisición de perfiles predominantemente partidarios o personales (Carey y Shugart 1995; Crisp et al. 2004). Así, a medida que las élites partidarias pierden 
control sobre las listas, la competencia personalista tiende a crecer; situación que se invierte cuando las dominan. Del mismo modo, la competencia interna decrecerá cuando los votos se agreguen alrededor del partido, y aumentará cuando esto no ocurra (ver tabla 1).

Finalmente, el nivel de competencia personalista desaparecerá cuando el elector cuente solamente con un voto asignable a un partido y, por el contrario, aumentará en aquellos casos en que cuente con múltiples posibilidades de sufragio, alcanzando su punto máximo cuando solo pueda expresar una preferencia por un candidato dentro de una lista partidaria (Carey y Shugart 1995; Crisp et al. 2004; Shugart 2005)..

Tabla 1. Incentivos institucionales para cultivar un perfil partidista o personalista

\begin{tabular}{|c|c|c|c|c|c|c|c|}
\hline \multirow{4}{*}{$\begin{array}{l}\text { Tendencia en } \\
\text { lo referido a la } \\
\text { competencia } \\
\text { personalista }\end{array}$} & & Tipo de tarjetón & & $\begin{array}{c}\text { Tipo de agrega- } \\
\text { ción }\end{array}$ & & Tipo de voto & \\
\hline & Alta & $\begin{array}{l}\text {-Lista donde la } \\
\text { nominación de } \\
\text { candidatos no } \\
\text { es presentada } \\
\text { por los líderes } \\
\text { partidarios }\end{array}$ & 4 & $\begin{array}{l}\text {-Sin agregación. } \\
\text { Votación centra- } \\
\text { da en los candi- } \\
\text { datos }\end{array}$ & 4 & $\begin{array}{l}\text {-Un voto utilizable } \\
\text { para seleccionar } \\
\text { un candidato o } \\
\text { facción. }\end{array}$ & 4 \\
\hline & Media & $\begin{array}{l}\text {-Lista presentada } \\
\text { por los líderes } \\
\text { partidarios, pero } \\
\text { perturbable }\end{array}$ & & $\begin{array}{l}\text {-Centrada en seg- } \\
\text { mentos o faccio- } \\
\text { nes partidarias }\end{array}$ & & $\begin{array}{l}\text {-Más de un voto } \\
\text { utilizable en múl- } \\
\text { tiples candidatos } \\
\text { o listas }\end{array}$ & \\
\hline & Baja & $\begin{array}{l}\text {-Lista controlada } \\
\text { por los líderes } \\
\text { partidarios }\end{array}$ & & $\begin{array}{l}\text {-Centrada en el } \\
\text { partido o la lista }\end{array}$ & & $\begin{array}{l}\text {-Un voto utilizable } \\
\text { solo con una lista }\end{array}$ & \\
\hline
\end{tabular}

NOTA: La dirección de las flechas representa un aumento esperado de la competencia personalista.

Fuente: Milanese, Albarracín y Jaramillo (2014) con base en Carey y Shugart (1995).

\section{Magnitud distrital y umbrales legales}

Múltiples estudios han remarcado la relación entre la cantidad de escaños que se distribuyen en un distrito electoral (magnitud distrital, $\boldsymbol{M}$ ) y el número de partidos que efectivamente compiten por cargos públicos: a medida que crece la magnitud, aumenta la dispersión de los votos entre diferentes fuerzas, incrementándose, también, la fragmentación del sistema (Duverger 1954; Cox 1997, entre otros), mientras que a medida que $\boldsymbol{M}$ disminuye, tiende a incrementarse el porcentaje de votos (umbral fáctico) que un partido necesita para obtener un asiento, reduciéndose el número de fuerzas que efectivamente puede ganar uno de ellos.

La magnitud distrital también puede afectar el grado de competencia electoral personalista. En este sentido, en los casos de listas cerradas bloqueadas (closed lists), los incentivos para cultivar una reputación partidaria aumentan a medi- 
da que lo hace la magnitud, ya que disminuyen los estímulos que llevan a los candidatos a diferenciarse del resto de los miembros de su lista (Carey y Shugart 1995; Crisp et al. 2004; Shugart et al. 2005). Lo contrario sucede en el caso de las listas cerradas no bloqueadas o en el de las abiertas (open lists), donde el número de copartidarios con el que se debe competir aumenta a medida que lo hace el tamaño del distrito y, por lo tanto, se produce un incremento de la personalización y la competencia dentro del partido.

La existencia de barreras legales (umbrales) y, en menor medida, las denominadas fórmulas de conversión de votos en escaños también pueden afectar el nivel de fragmentación partidaria (Gallagher y Mitchell 2005); de hecho, los umbrales obligan a los partidos a superar un número mínimo de votos si pretenden obtener representación y pueden inducir a que políticos ambiciosos se aglutinen en un menor número de etiquetas partidarias, reduciendo la cantidad de partidos con capacidad real de competencia.

\section{REGLAS Y COMPETENCIA ELECTORAL EN COLOMBIA}

A pesar de la existencia de listas cerradas bloqueadas, el sistema vigente hasta 2003 en Colombia permitía a cada partido presentar múltiples listas en cada distrito e impedía la agregación de votos entre ellas. Esto, sumado a la existencia de distritos electorales con magnitudes iguales o mayores a dos y la frecuente elección de legisladores por residuo y no por cociente, hizo que el sistema funcionara, de facto, como uno de voto único no transferible o SNTV (Cox y Shugart 1995). Carey y Shugart (1995) consideraron que este "sistema de lista personal" era un caso extremo de competencia intrapartidaria de tipo personalista que fomentaba la competencia individual al distribuir escaños de acuerdo con el número de votos obtenidos por los candidatos (listas personales) y no por los partidos. La ausencia de mecanismos de cooperación interna producía incentivos para que cada candidato, en este caso las cabezas de lista, compitieran poniendo énfasis en sus atributos personales, inclusive en contra de sus copartidarios.

A pesar de estas reglas, el sistema se caracterizó durante décadas por dinámicas de competencia intrapartidaria de carácter faccional (Gutiérrez Sanín 2007; Moreno y Escobar-Lemmon 2008). Fueron los razonables niveles de institucionalización que exhibieron estas facciones lo que garantizó la coordinación dentro de los partidos tradicionales (Pachón 2004; Moreno y Escobar-Lemmon 2008), permitiéndoles aprovechar las reglas electorales para tener una sobre proporción de escaños (Shugart et al. 2007). Sin embargo, el progresivo desgaste de estas estructuras faccionales, en un contexto institucional formal que favorecía la fragmentación y personalización (Cox y Shugart 1995), llevó al incremento desproporcionado del número de listas partidarias (Botero et al. 2016).

Asimismo, las clásicas estructuras que conectaban el nivel nacional y subnacional de los partidos se fueron debilitando, dando paso a nuevos tipos de organi- 
zaciones partidarias mucho más descentralizadas (Leal Buitrago y Dávila 1990; Gutiérrez Sanín 2007; Dargent y Muñoz 2011). Esto se tradujo en una pérdida de control por parte de los partidos del uso de su etiqueta y en el surgimiento de innumerables pequeños movimientos de carácter personal denominados "microempresas electorales" (Pizarro 2002).

Este proceso representó el zenith de la desinstitucionalización del sistema que se vio reflejado en un incremento considerable de la fragmentación partidaria y de un sensible incremento en la volatilidad del voto (Albarracín et al. 2018), acompañados de una creciente pérdida de congruencia internivel de los partidos (Milanese y Albarracín 2020). Las desventajas que las reglas electorales presentaban para los partidos y políticos tradicionales facilitaron la aprobación de una reforma al sistema electoral en 2003 - ver Tabla 2 - que buscaba reducir la creciente fragmentación electoral y la competencia intrapartidaria personalista (Shugart et al. 2007; Botero y Rodríguez Raga 2008). La reforma, que aplicó para todas las elecciones en Colombia, introdujo nuevos arreglos institucionales como la presentación de listas únicas por partido, el establecimiento de umbrales legales, una nueva fórmula de conversión y la posibilidad de presentar listas cerradas no bloqueadas (open lists).

Tabla 2. Síntesis de los cambios institucionales producidos por el Acto Legislativo $\mathrm{N}^{\circ} 1$ de 2003

\begin{tabular}{|c|c|c|c|}
\hline & Condición prereforma & Condición posreforma & $\begin{array}{c}\text { Efecto de corrección } \\
\text { esperado }\end{array}$ \\
\hline \multirow{2}{*}{$\begin{array}{l}\text { Tipo de } \\
\text { lista }\end{array}$} & Cerrada bloqueada. & $\begin{array}{l}\text { Cerrada no bloqueada (abierta de } \\
\text { acuerdo con el Acto Legislativo). }\end{array}$ & \multirow{2}{*}{$\begin{array}{l}\text { Reducir y ordenar el } \\
\text { número de listas }\end{array}$} \\
\hline & $\begin{array}{l}\text { Listas múltiples por } \\
\text { partido }\end{array}$ & $\begin{array}{l}\text { Posibilidad de expresar preferencia } \\
\text { por un candidato dentro de la lista }\end{array}$ & \\
\hline $\begin{array}{l}\text { Fórmula de } \\
\text { conversión }\end{array}$ & Cuota Hare & Cifra repartidora $\left(d^{\prime} H o n d t\right)$ & $\begin{array}{l}\text { Reducir la proporcio- } \\
\text { nalidad premiando a } \\
\text { los partidos grandes }\end{array}$ \\
\hline \multirow{3}{*}{$\begin{array}{l}\text { Barreras } \\
\text { legales }\end{array}$} & \multirow{3}{*}{ Inexistentes } & $\begin{array}{l}2 \% \text { del total de los votos válidos } \\
\text { (Senado), } 3 \% \text { desde } 2009 .\end{array}$ & \multirow{3}{*}{$\begin{array}{l}\text { Reducir la proporcio- } \\
\text { nalidad eliminando a } \\
\text { los partidos más pe- } \\
\text { queños }\end{array}$} \\
\hline & & $\begin{array}{l}30 \% \text { o } 50 \% \text { del cociente de acuer- } \\
\text { do con } M \text { (Cámara de Representan- } \\
\text { tes). }\end{array}$ & \\
\hline & & $\begin{array}{l}50 \% \text { del cociente Asambleas y } \\
\text { Concejos }\end{array}$ & \\
\hline
\end{tabular}

Fuente: elaboración propia con base en Milanese y Jaramillo (2015).

Paradójicamente, una reforma que fue diseñada para reducir la fragmentación del sistema y fomentar la cooperación intrapartidaria introdujo, simultáneamente, algunos elementos que mantuvieron las tendencias personalistas (Rodríguez Raga 2006). El efecto cohesionador de las listas únicas fue debilitado por la posibilidad de expresar preferencias por candidatos dentro de ellas. Así, si las primeras producían estrategias cooperativas, la segunda se encargó de 
atizar la competencia intrapartidaria. No obstante, se esperaba que las características del nuevo sistema electoral produjeran una disminución de la personalización en la competencia interna de los partidos, así como una disminución en la fragmentación partidaria en todos los niveles (ver Tabla 3).

Tabla 3. Proyección teórica de los niveles de competencia interna pre y pos 2003

\begin{tabular}{lllll}
\hline & \multicolumn{2}{c}{ Tipo de tarjetón } & Tipo de agregación & \multicolumn{1}{c}{ Tipo de voto } \\
\cline { 2 - 5 } & Alta & $\begin{array}{l}\text { Lista donde la no- } \\
\text { minación de candi- } \\
\text { datos no es presen- } \\
\text { tada por los líderes } \\
\text { Tendencia en } \\
\begin{array}{l}\text { lo referido a la } \\
\text { competencia } \\
\text { intrapartidaria }\end{array}\end{array}$ & $\begin{array}{l}\text { Sin agregación. Vo- } \\
\text { tación centrada en } \\
\text { los candidatos }\end{array}$ & $\begin{array}{l}\text { Un voto utilizable } \\
\text { para seleccionar un } \\
\text { candidato o facción }\end{array}$ \\
& Media & $\begin{array}{l}\text { Lista presentada } \\
\text { por los líderes par- } \\
\text { tidarios, pero per- } \\
\text { turbable } \\
\text { Lista controlada } \\
\text { por los líderes par- } \\
\text { tidarios }\end{array}$ & $\begin{array}{l}\text { Centrada en seg- } \\
\text { mentos o facciones } \\
\text { partidarias }\end{array}$ & $\begin{array}{l}\text { Más de un voto } \\
\text { utilizable en múl- } \\
\text { tiples candidatos o } \\
\text { listas }\end{array}$ \\
\hline
\end{tabular}

Fuente: Milanese, Albarracín y Jaramillo (2014) con base en Carey y Shugart (1995) y Shugart, et al. 2007. Convenciones: Pre 2003 Pos 2003 Combinación Pre y Pos 2003

Si se incluye en el análisis a la magnitud de los distritos electorales, elemento que la reforma no afectó, se esperaría que tanto antes como después de la reforma de 2003 existiera una tendencia al aumento de la competencia dentro de los partidos y la fragmentación partidaria a medida que $M$ se incrementara.

Así, debería esperarse que:

A mayor magnitud distrital más alto nivel de competencia intrapartidaria personalista, así como una mayor fragmentación del sistema de partidos (Hipótesis 1).

Después de la reforma existiera una reducción en los niveles de competencia intrapartidaria personalista, así como un menor grado de fragmentación del sistema de partidos (Hipótesis 2).

Efectivamente, en las elecciones del Senado ocurrió la esperada reducción en la fragmentación partidaria (Hoskin y García 2006; Hoyos 2007; Shugart et al. 2007; Wills 2009; Batlle y Puyana 2013). Sin embargo, ese efecto no se produjo en elecciones para la Cámara Baja (Cámara de Representantes), caracterizadas por una dinámica mucho más regional. En este caso, Pachón y Shugart (2010) mostraron que, de modo similar al Senado, en los distritos electorales de mayor magnitud se redujo la fragmentación partidaria, aunque aumentó la competencia interna en los partidos. No obstante, de manera simultánea, en aquellos más pequeños existió un aumento de la fragmentación partidaria acompañada por una reducción de la intrapartidaria. 
De este modo, en los distritos más pequeños la agregación de votos en las listas partidarias incentivó a un número significativo de políticos a buscar diferentes "etiquetas" (aumentando la fragmentación) en lugar de cooperar con rivales dentro de un mismo partido. A partir de estos resultados se puede esperar que:

A mayor nivel de fragmentación del sistema de partidos menor nivel de competencia personalista intrapartidaria (Hipótesis 3).

\section{LA POLÍTICA ELECTORAL SUBNACIONAL Y LOS EFECTOS INSTITUCIONALES}

Las reformas institucionales descritas anteriormente fueron diseñadas e implementadas pensando en las elecciones y en el sistema de partidos desde un punto de vista nacional, asumiendo que los efectos producidos debían ser idénticos en elecciones municipales y departamentales. Empero, otros cambios institucionales formales, como una mayor descentralización (Dargent y Muñoz 2011) o informales, como las estructuras clientelistas o mecanismos de financiación ligados a economías ilegales (Leal Buitrago y Dávila 1990; Albarracín et al. 2018), debilitaron los nexos entre los niveles nacionales y locales de los partidos. De esta manera, la política electoral subnacional adquirió dinámicas propias, muy distintas a la nacional (Gutiérrez Sanín 2001; Botero y Alvira 2011).

Ante esta situación, esperar efectos similares de las reglas electorales en los niveles apenas señalados es un supuesto difícil de sostener. De hecho, análisis previos muestran que la fragmentación en las elecciones de concejos municipales creció en promedio después de la reforma de 2003. Esto ocurrió también en los casos con mayores magnitudes (Milanese y Jaramillo 2015; Milanese y Batlle 2018; Albarracín 2020) rompiendo con el patrón señalado en la Cámara de Representantes. Según estos resultados, las instituciones formales pensadas desde el nivel nacional no solo no tuvieron los efectos deseados en el subnacional, sino que también produjeron los opuestos. A partir de estos estudios subnacionales puede esperarse que:

Exista un mayor nivel de fragmentación del sistema de partidos en las elecciones locales posteriores a la reforma electoral de 2003, independientemente de la magnitud distrital (Hipótesis 4).

\section{ANÁLISIS CUANTITATIVO EN LAS ELECCIONES MUNICIPALES}

\section{Datos y medición de la fragmentación entre y dentro de los partidos}

Para evaluar el impacto que tuvieron las reformas institucionales en los niveles de fragmentación partidaria y competencia dentro de los partidos en las elec- 
ciones locales (concejos municipales) se revisaron los resultados de seis comicios (1997-2015) en todos los municipios del país $(\sim 1,100)$ proporcionados por Pachón y Sánchez (2014). ${ }^{3}$

Tradicionalmente, se ha medido el nivel de fragmentación del sistema con el número efectivo de partidos (Laakso y Taagepera 1979). ${ }^{4}$ Sin embargo, hay menos consenso respecto a la medición de la competencia interna de los partidos. El frecuente uso del número nominal de candidatos por lista partidaria es un indicador subóptimo, ya que un partido puede tener un gran número de candidatos, pero pocos fuertes que atraigan todos los votos. En este caso, la medida señalaría un alto grado de competencia interna cuando realmente no la hay. Pachón y Shugart (2010) utilizan la razón del primer perdedor como su indicador de competencia intrapartidaria. En este, el número de votos del primer candidato perdedor de una lista se divide por los votos del ganador. Entre mayor sea la diferencia entre los candidatos menor será el valor.

En el presente trabajo se identifica la fragmentación que existe dentro de las listas partidarias, que no puede medirse con las propuestas anteriores. Para eso, se desarrolló un indicador: el número efectivo de candidatos ponderado, basado en el cálculo del número efectivo de partidos. Dado que en Colombia se reportan los votos que obtuvo cada lista partidaria y cada candidato dentro de la lista, podemos calcular que tan dispersos o concentrados están dentro de ellas. En un primer paso se calcula la fragmentación de un partido $i$ en el municipio $m$ según la fórmula:

$$
N E C_{i, m}=\frac{1}{\sum_{j=1}^{n} c_{j}^{2}}
$$

La variable $\mathbf{c}_{\mathrm{j}}$ corresponde a la proporción de votos del partido $\boldsymbol{i}$ obtenida por el candidato $j .{ }^{5}$ Antes de 2003, el sistema colombiano se caracterizaba por tener listas cerradas, pero con la posibilidad de presentar múltiples listas de un mismo partido en cada distrito electoral. Ante esto, para las elecciones previas a $2003 c_{j}$ es la proporción de los votos que ganó la lista $\mathbf{j}$ del total de votos que obtuvieron todas las listas del partido $i$ en el municipio $m$. Aunque el $c_{j}$ antes y después de 2003 no es idéntico es lo suficientemente similar para garantizar comparabilidad. Esto se debe a que antes de la reforma, y en particular desde mediados de los noventa, más que listas en el sentido convencional estas eran

Se excluye en el análisis a Bogotá, ciudad que tiene un tamaño y magnitud distrital mucho más altos que los otros municipios, así como los corregimientos departamentales en la Amazonía y la Orinoquia donde no se celebran elecciones municipales.

$4 \quad$ Esta medida es un promedio del número de partidos que participan en la elección ponderado por el porcentaje de votos obtenido por cada uno de ellos. Para nuestro análisis calculamos el número efectivo de partidos para cada municipio en las elecciones de los concejos municipales.

Dado que se analiza la dispersión de votos entre candidatos de un partido, se excluyeron del cálculo aquellos obtenidos solamente por la lista partidaria, es decir, aquellos casos en que el elector no marcó una opción preferente por un candidato desde las elecciones de 2003. Si un partido se decidió por cerrar y bloquear sus listas, se le asigna, automáticamente, un número efectivo de candidatos igual a cero. 
vehículos personalistas de un candidato. Usualmente (alrededor del $95 \%$ de los casos), cada lista exitosa elegía solo un candidato, lo que hace que el cálculo se asemeje al del número de candidatos en el escenario pos 2003.

En un segundo paso, se calculó el número efectivo de candidatos promedio del municipio, como un promedio del número efectivo de candidatos de todos los partidos en el mismo distrito, ponderado por el porcentaje de votos que obtuvo el partido en la elección:

$$
N E C_{m}=\sum_{i=1}^{n} v_{i, m} \cdot N E C_{i, m}
$$

En esta fórmula, $v_{i}$ es la proporción de votos del partido $i$ en el municipio $m$. Se decidió ponderar el promedio de los números efectivos de candidatos para darles más peso a partidos electoralmente más relevantes.

Para evaluar el impacto de las nuevas reglas electorales se utiliza una variable dummy que distingue las elecciones que ocurren antes y después de la reforma de 2003. Basados en información de la Registraduría Nacional del Estado Civil se definió la magnitud de todos los distritos; cada uno corresponde perfectamente con un municipio del país.

\section{Modelos de regresión con efectos fijos}

Primero exploramos si hubo cambios promedio en la fragmentación partidaria y la competencia dentro de partidos en los municipios con la reforma. Para esto, se utilizaron modelos de efectos fijos para datos panel con errores estándar agrupados por municipio que nos permiten controlar por características no observadas de cada municipio que puedan afectar el nivel de competencia. Para comprobar si la selección del modelo era la apropiada se realizaron pruebas diagnósticas y probamos otros modelos que indicaron resultados consistentes con aquellos del modelo de efectos fijos. ${ }^{6}$

Los resultados (ver Tabla 4, Modelo 1) muestran un considerable incremento de la competencia interna de los partidos después de la reforma de 2003. De hecho, en promedio, el número efectivo de candidatos creció 7.56 puntos después de esta. Adicionalmente, puede apreciarse que el impacto de la magnitud distrital sobre la competencia también varía después de la reforma. Antes del cambio institucional, a medida que aumentaba la magnitud, era mayor la dispersión de

\footnotetext{
Según los resultados de la prueba Breush-Pagan, un modelo OLS no sería apropiado para el análisis. Las pruebas de Hausman y Sargan-Hansen indican que el modelo de efectos fijos es apropiado y preferible a un modelo con efectos aleatorios. Siguiendo el trabajo de Pachón y Shugart (2010) también realizamos modelos GEE (generalized estimating equations). Estos modelos pueden ser más flexibles, permitiendo el uso de diferentes estructuras de correlación (Zorn 2001). También se corrieron los modelos usando variables transformadas por logaritmos sin encontrar diferencias en los resultados.
} 
votos dentro los partidos, es decir, los municipios más grandes tenían un mayor grado de competencia interna. Empero, posterior al 2003, los municipios de diferente magnitud empezaron a comportarse de manera similar. En promedio, municipios con mayor $\boldsymbol{M}$ tienen menor competencia personalista que antes de la reforma, mientras que en municipios con menor $\boldsymbol{M}$ aumentó la competencia dentro de los partidos.

Tabla 4. Resultados de regresiones con efectos fijos

\begin{tabular}{lcc}
\hline & $\begin{array}{c}\text { Modelo 1 } \\
\text { Número Efectivo de } \\
\text { Candidatos (NEC) }\end{array}$ & $\begin{array}{c}\text { Modelo 2 } \\
\text { Número }\end{array}$ \\
\hline Magnitud & $0.616^{* * *}$ & -0.059 \\
& $(0.098)$ & $(0.034)$ \\
Reforma Política & $7.56^{* * *}$ & $1.085^{* * *}$ \\
Reforma x Magnitud & $(0.656)$ & $(0.155)$ \\
Número efectivo de partidos & $-0.606^{* * *}$ & $0.069^{* * *}$ \\
Número efectivo de candidatos & $(0.0597)$ & $(0.015)$ \\
& $-1.223^{* * *}$ & - \\
Constante & $(0.0536)$ & - \\
Observaciones & - & $-0.162^{* * *}$ \\
& - & $(0.006)$ \\
& $4.934^{* * *}$ & $0.70^{* * *}$ \\
\hline
\end{tabular}

${ }^{*} \mathrm{p}<0.05,{ }^{* *} \mathrm{p}<0.01,{ }^{* * *} \mathrm{p}<0.001$. Errores estándar agrupados por municipio en paréntesis.

Como lo indica la línea negra, casi plana, en el Gráfico 1, existe, desde entonces, una ligera diferencia entre municipios grandes y pequeños en cuanto a la competencia intrapartidaria. La reforma no redujo, sino que aumentó la competencia personalista y homogenizó a los municipios en esta dimensión.

Gráfico 1. Número efectivo de candidatos estimado según magnitud antes (línea punteada) y después (línea sólida) de 2003

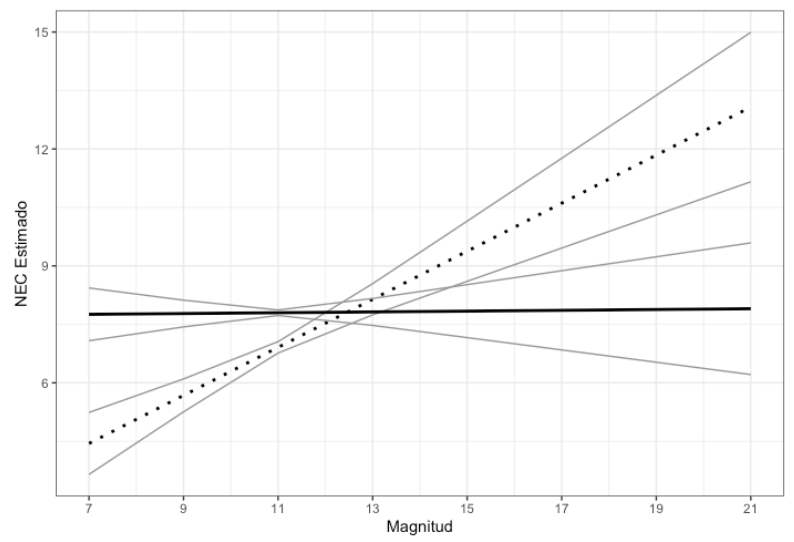


Contrario a las expectativas, nuestros resultados (ver Tabla 4, Modelo 2) también indican que la fragmentación del sistema de partidos aumentó en las elecciones de concejos municipales. A su vez, se observa que el efecto de $\boldsymbol{M}$ sobre la fragmentación solo es relevante después de la reforma, ya que antes de ella no se podían distinguir diferencias estadísticamente significativas en la fragmentación partidaria entre distritos electorales pequeños y grandes. De hecho, tras la reforma los municipios más grandes tienden a estar más fragmentados. Esto es, que mientras que en lo referido a la competencia interna existe un efecto homogeneizador entre municipios de distintos tamaños después de 2003, en la fragmentación partidaria se vuelven más disimiles.

Gráfico 2. Número efectivo de partidos estimado según magnitud antes (línea punteada) y después (línea sólida) de 2003

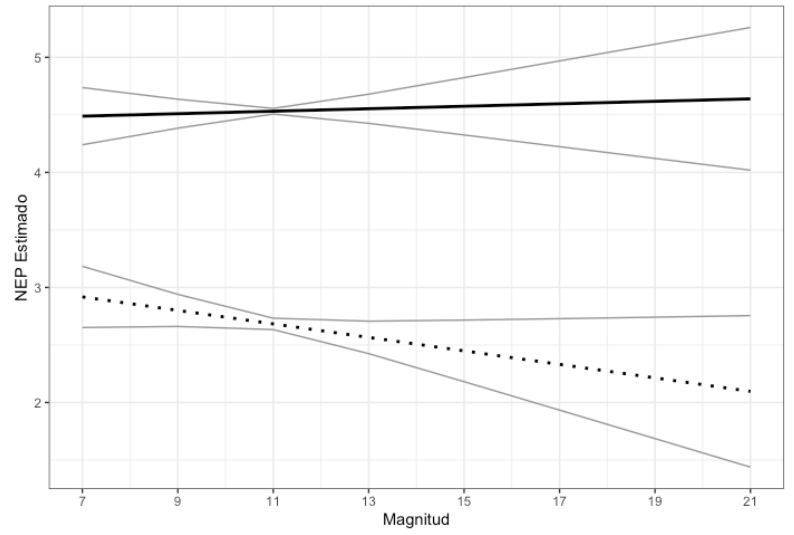

Finalmente, también se encuentra, tal como lo hicieran previamente Pachón y Shugart (2010) en su estudio sobre las elecciones a la Cámara de Representantes, que existe una relación negativa entre la fragmentación partidaria y la competencia dentro de ellos: a medida que aumenta la primera puede apreciarse un decrecimiento de la fragmentación de los votos dentro de los partidos.

\section{Modelos de regresión geográficamente ponderados}

Hasta ahora hemos podido establecer el impacto promedio que tuvo la reforma electoral en las elecciones de los concejos municipales. No obstante, también es importante determinar si hubo variaciones espaciales asociadas a ese impacto. Esto es especialmente relevante en un país como Colombia porque existen marcadas especificidades y asimetrías desde el punto de vista regional y local que inciden en múltiples dimensiones de la vida social (CINEP 1998; Clavijo García 2007), incluyendo dentro de ellas a las elecciones.

Para esto, se utilizaron modelos de regresión geográficamente ponderada (GWR). A diferencia de los modelos de efecto fijos, estos permiten realizar el 
cálculo de un $\beta$ local para cada unidad de análisis (municipios), posibilitando apreciar cómo estos (los $\beta$ ) pueden variar desde un punto de vista espacial (Fotheringham et al. 2002; De Smith et al. 2018; Harbers e Ingram 2019). Este tipo de estimación cuestiona el supuesto teórico de los modelos estándar (globales) que asume que los efectos de las variables pueden ser interpretados de forma homogénea en la totalidad del espacio geográfico y establecen ecuaciones individuales para cada unidad de análisis (Fotheringham et al. 2002). De este modo, puede evaluarse si el impacto sobre cada una de estas unidades geográficas que poseen los "vecinos" más cercanos es mayor que el de aquellos más distantes, y si los comportamientos son de carácter nacional, regional o local.

Las GWR permiten evitar los problemas asociados a la dependencia espacial, cuestión especialmente relevante cuando, como sucede en este caso, se hace referencia a procesos (y, por lo tanto, a datos) que no son estacionarios. ${ }^{7}$ A diferencia de los modelos globales ofrecen la posibilidad de analizar un $N$ amplio sin renunciar a la identificación de especificidades gracias al cálculo del coeficiente $\beta$ de cada variable independiente en cada unidad de análisis. De esta manera, su utilización representa el tránsito de un estudio de carácter general, como el realizado hasta este punto, a otro de tipo local que permita alcanzar conclusiones más precisas en el ámbito subnacional.

Los resultados obtenidos son relativamente homogéneos en lo que se refiere a los efectos (signo de los $\beta$ ) de las magnitudes distritales y de la fragmentación partidaria sobre el grado de competencia personalista. ${ }^{8}$ Tanto antes como después de la reforma un aumento de la fragmentación del sistema partidario estuvo asociado con una menor intensidad de la competencia intrapartidaria (ver Tabla 5), ${ }^{9}$ mostrando una evidente similitud con los resultados de la regresión con efectos fijos. Desde este punto de vista, aunque no sea el objetivo de su uso, las GWR funcionan también como un chequeo de la robustez de los modelos previamente utilizados.

Un fenómeno es estacionario cuando el nivel promedio de la variable con que se le mide es constante en todas las unidades de análisis del área de estudio.

$8 \quad$ La mayor bondad del ajuste de los modelos locales pudo ser comprobada a través de los valores del criterio de información de Akaike que son sistemáticamente menores que los de las OLS, lo mismo sucede con el coeficiente I de Moran de los errores estándar que, además, no es significativa en los modelos globales.

9 En la tabla puede apreciarse la agrupación en cuantiles de los coeficientes de regresión. De ese modo, se observa la heterogeneidad de los resultados que pasa desapercibida en las OLS 
Tabla 5. Resultados de regresiones geográficamente ponderadas (NEC) por año. ${ }^{10}$

\begin{tabular}{|c|c|c|c|c|c|c|}
\hline & Mínimo & Cuartil bajo & Mediana & Cuartil alto & Máximo & Diff of criterion \\
\hline \multicolumn{7}{|c|}{1997} \\
\hline NEP & $-10,826180$ & $-4,331237$ & $-3,051395$ & $-2,139711$ & $-0,057733$ & $-38,988102$ \\
\hline Magnitud & $-0,439173$ & 0,971158 & 1,376924 & 1,745185 & 3,742770 & $-41,497942$ \\
\hline Población & $-0,000019$ & 0,000007 & 0,000029 & 0,000074 & 0,000725 & $-45,016023$ \\
\hline Constante & $-16,201299$ & $-2,936141$ & $-0,287806$ & 2,670385 & 21,340994 & $-115,426559$ \\
\hline \multicolumn{7}{|c|}{2000} \\
\hline NEP & $-7,688276$ & $-2,676115$ & $-2,066403$ & $-1,744008$ & $-0,479299$ & $-32,009800$ \\
\hline Magnitud & $-0,351256$ & 0,766974 & 1,138405 & 1,481453 & 3,171632 & $-29,886072$ \\
\hline Población & $-0,000034$ & 0,000000 & 0,000006 & 0,000031 & 0,000504 & $-24,504646$ \\
\hline Constante & $-11,807969$ & $-11,807969$ & 0,728246 & 3,222298 & 15,134280 & $-73,824266$ \\
\hline \multicolumn{7}{|c|}{2003} \\
\hline NEP & $-0,761020$ & $-0,582935$ & $-0,443607$ & $-0,302471$ & 0,026938 & $-25,161151$ \\
\hline Magnitud $^{+}$ & 0,325276 & 0,491647 & 0,543189 & 0,610433 & 0,776796 & $-22,115832$ \\
\hline Población & $-0,000018$ & $-0,000001$ & 0,000001 & 0,000004 & 0,000039 & 3,628195 \\
\hline Constante & $-0,452750$ & 1,427269 & 2,011137 & 2,668824 & 4,878577 & $-28,901975$ \\
\hline \multicolumn{7}{|c|}{2007} \\
\hline NEP & $-0,490046$ & $-0,289548$ & $-0,225408$ & $-0,156278$ & 0,405592 & $-17,435865$ \\
\hline Magnitud & 0,277844 & 0,533025 & 0,611821 & 0,646591 & 0,808771 & $-6,530580$ \\
\hline Población & $-0,000012$ & $-0,000002$ & $-0,000001$ & 0,000003 & 0,000036 & $-20,090495$ \\
\hline Constante & $-1,265185$ & 0,909207 & 1,330430 & 2,040532 & 3,463799 & $-9,945577$ \\
\hline \multicolumn{7}{|c|}{2011} \\
\hline NEP & $-1,083627$ & $-0,372657$ & $-0,275798$ & $-0,198474$ & 0,052498 & $-17,531246$ \\
\hline Magnitud & 0,367643 & 0,679612 & 0,749875 & 0,836406 & 1,369984 & $-19,168203$ \\
\hline Población $^{+}$ & $-0,000007$ & $-0,000001$ & 0 & 0,000003 & 0,000048 & 5,777740 \\
\hline Constante & $-3,643237$ & $-0,172787$ & 0,875735 & 1,725152 & 4,226187 & $-25,215456$ \\
\hline \multicolumn{7}{|c|}{2015} \\
\hline NEP & $-0,518962$ & $-0,286943$ & $-0,220362$ & $-0,126325$ & 0,002709 & $-16,751291$ \\
\hline Magnitud & 0,387771 & 0,527651 & 0,606569 & 0,660034 & 0,776221 & $-10,635950$ \\
\hline Población $^{+}$ & $-0,000019$ & $-0,000005$ & $-0,000002$ & 0,000001 & 0,000014 & 5,194889 \\
\hline Constante & $-0,361496$ & 0,939342 & 1,170499 & 1,466011 & 2,512770 & $-85,961782$ \\
\hline
\end{tabular}

Sin embargo, cabe señalar que parecen existir variaciones asociadas a la reforma. De hecho, desde las elecciones celebradas en 2003 puede apreciarse un sensible decrecimiento (promedio) de la intensidad del impacto de la fragmentación partidaria, acompañado por una homogenización de los valores de los $\beta$ (y, por lo tanto, de los efectos sistémicos).

También es importante destacar que, como puede ser apreciado en el Mapa 1, existen efectos regionales asociados a las mencionadas variaciones. Es decir,

10 Interceptos y variables independientes presentan una variabilidad significativa en su $\beta$ a nivel espacial a excepción de las variables magnitud (2003) y población (2011 y 2015), indicadas por el símbolo t. Si el valor en la última columna ("diff of criterion") es negativo, la variable es espacialmente significativa. No se aprecian problemas de multicolinealidad local (distinguible por los números de condición inferiores a 30). Esto permitió que el ancho de banda AIC resuelva una cantidad y distancia de vecinos óptima en lugar de utilizar una matriz de pesos predeterminada. 
que no solo hay impactos diferenciales de la fragmentación partidaria sobre la competencia personalista entre los municipios, ya que estos muestran, además, distintas concentraciones en áreas geográficas razonablemente bien definidas. Empero, puede resaltarse que este patrón de regionalización fue temporalmente estable en las elecciones antes de la reforma, disolviéndose esta característica después de 2003.

Desde este punto de vista, el ciclo prereforma se caracterizó en el grueso del país por un efecto negativo de la fragmentación partidaria sobre el número efectivo de candidatos, especialmente en la Orinoquía (más precisamente en los departamentos de Vichada, Arauca y Casanare) y, en menor medida, en el Caribe (con mayor énfasis en la Guajira, sur de Córdoba, norte de Cesar y en Magdalena). Por el contrario, en Caquetá, Putumayo y sur del Cauca, pese a que se pudo apreciar un impacto negativo, este fue visiblemente menor.

Después de 2003, los valores, aunque continuaron siendo predominantemente negativos, se acercaron visiblemente a cero. Incluso, una no despreciable proporción de ellos, ligeramente mayor al $25 \%$, experimentó un efecto positivo. No obstante, si bien puede notarse la presencia de manchas geográficamente bien distinguibles, estas no se sostuvieron a lo largo del tiempo

Es preciso señalar que es difícil encontrar las especificidades regionales que producen este tipo de variaciones, cosa que además excedería las expectativas del presente trabajo. Para lograrlo debería realizarse un análisis cualitativo mucho más intenso en estas regiones, abriéndose un nuevo frente de preguntas asociadas al evidente efecto geográfico que no puede pasar desapercibido.

Mapa 1. Efectos de NEP sobre número efectivo de candidatos (GWR)

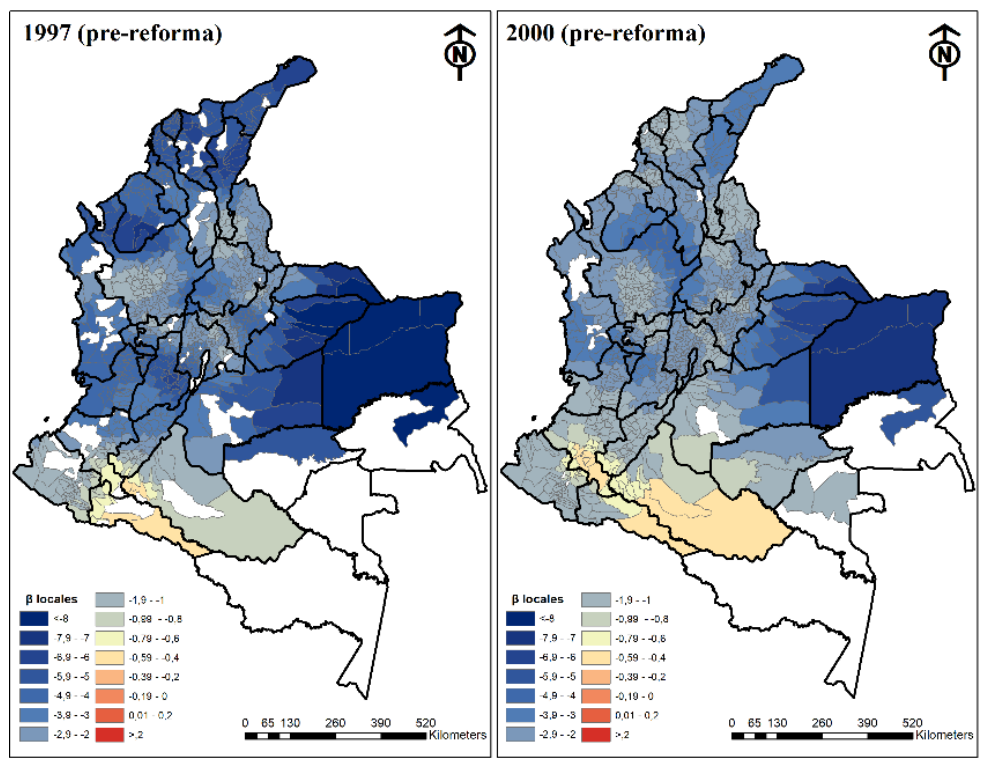




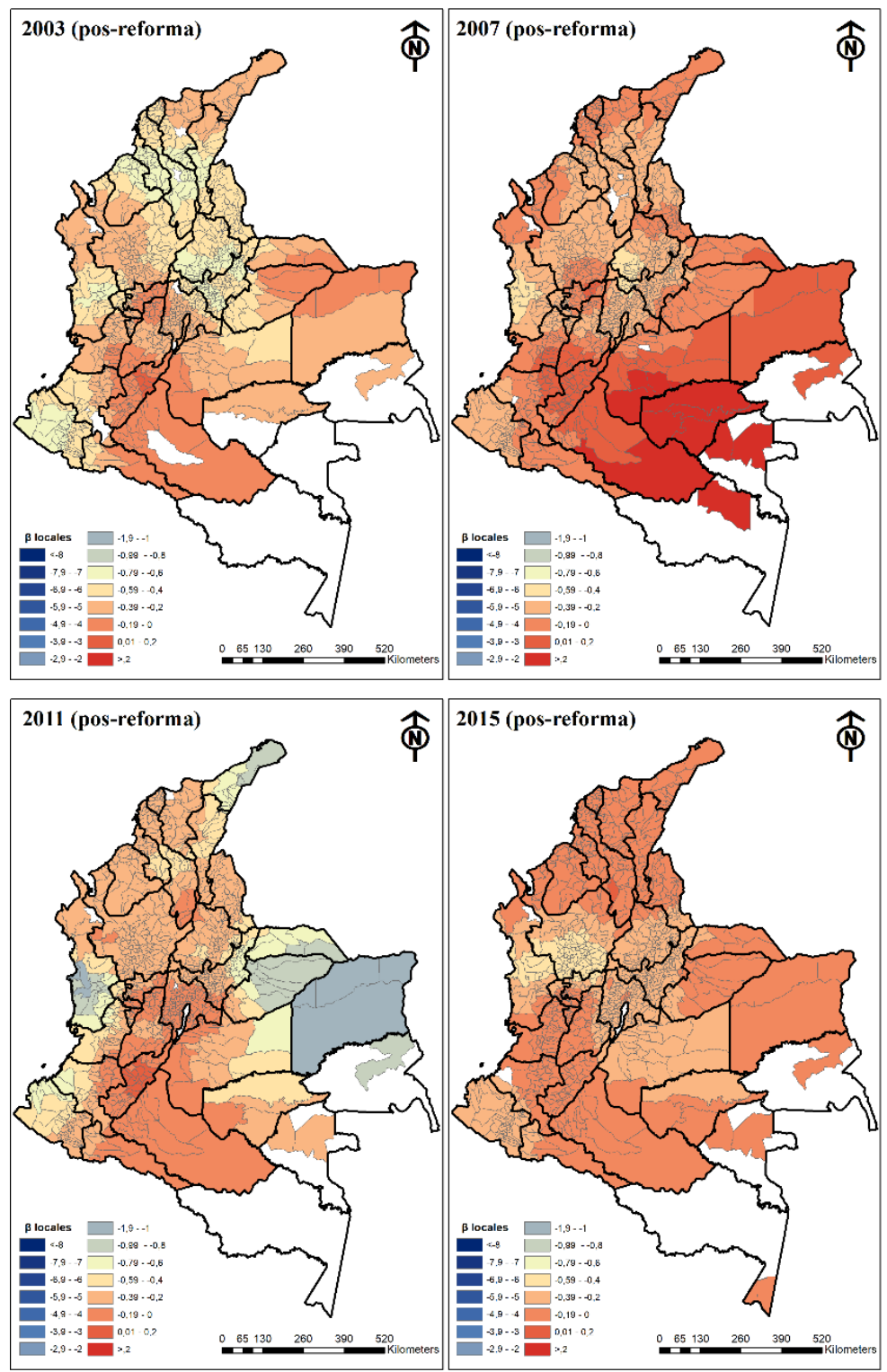

La magnitud también está directamente relacionada con un incremento de la competencia personalista. Del mismo modo que sucede con la fragmentación partidaria, también puede notarse que después de la reforma se reduce la dispersión de los valores de los coeficientes de regresión, mostrando así una relativa homogenización del efecto de $\boldsymbol{M}$ sobre la competencia personalista en los municipios (ver Gráfico 3). 
Gráfico 3. Efectos de la magnitud sobre número efectivo de candidatos según magnitud (GWR)
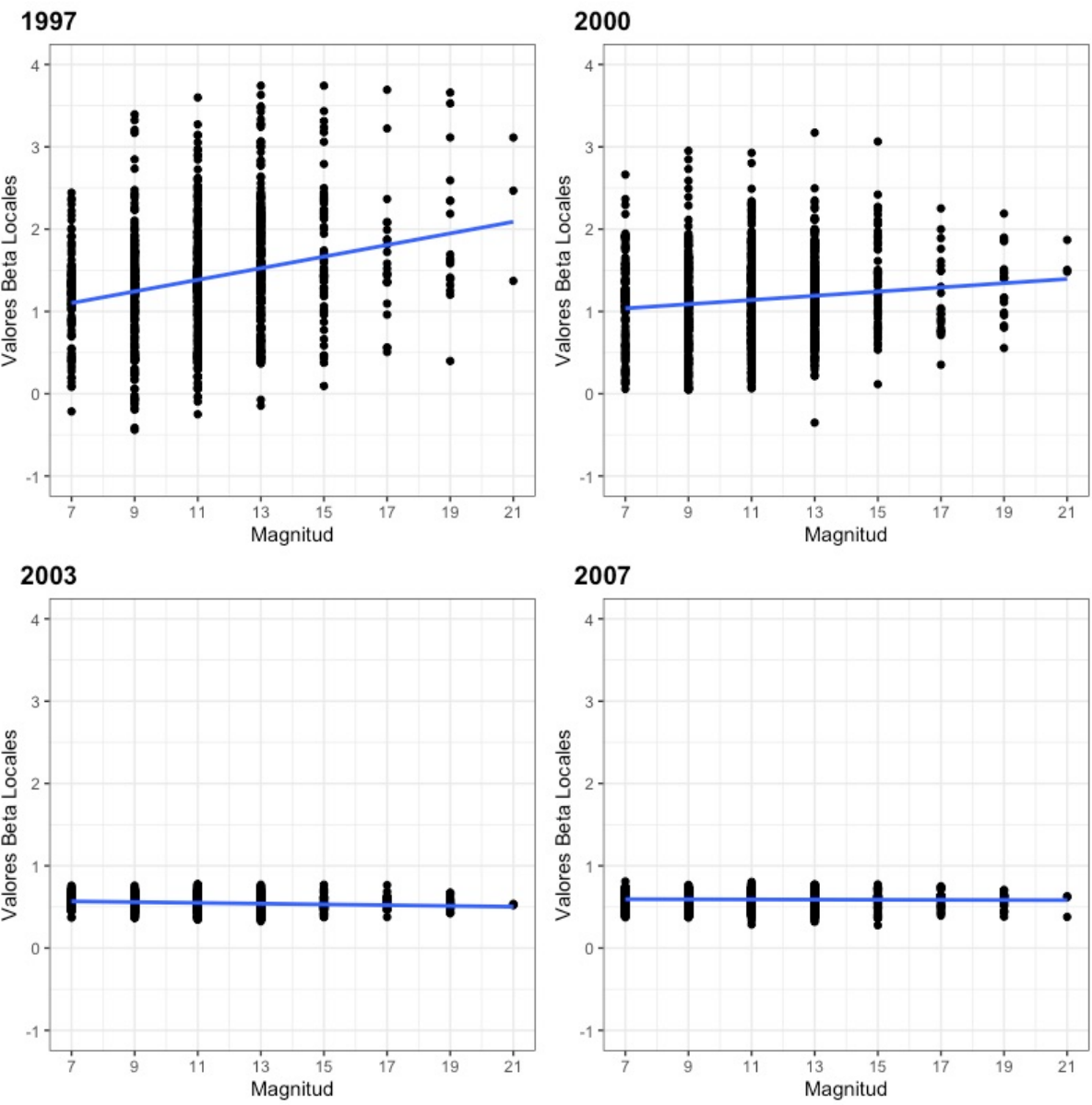

$$
2007
$$
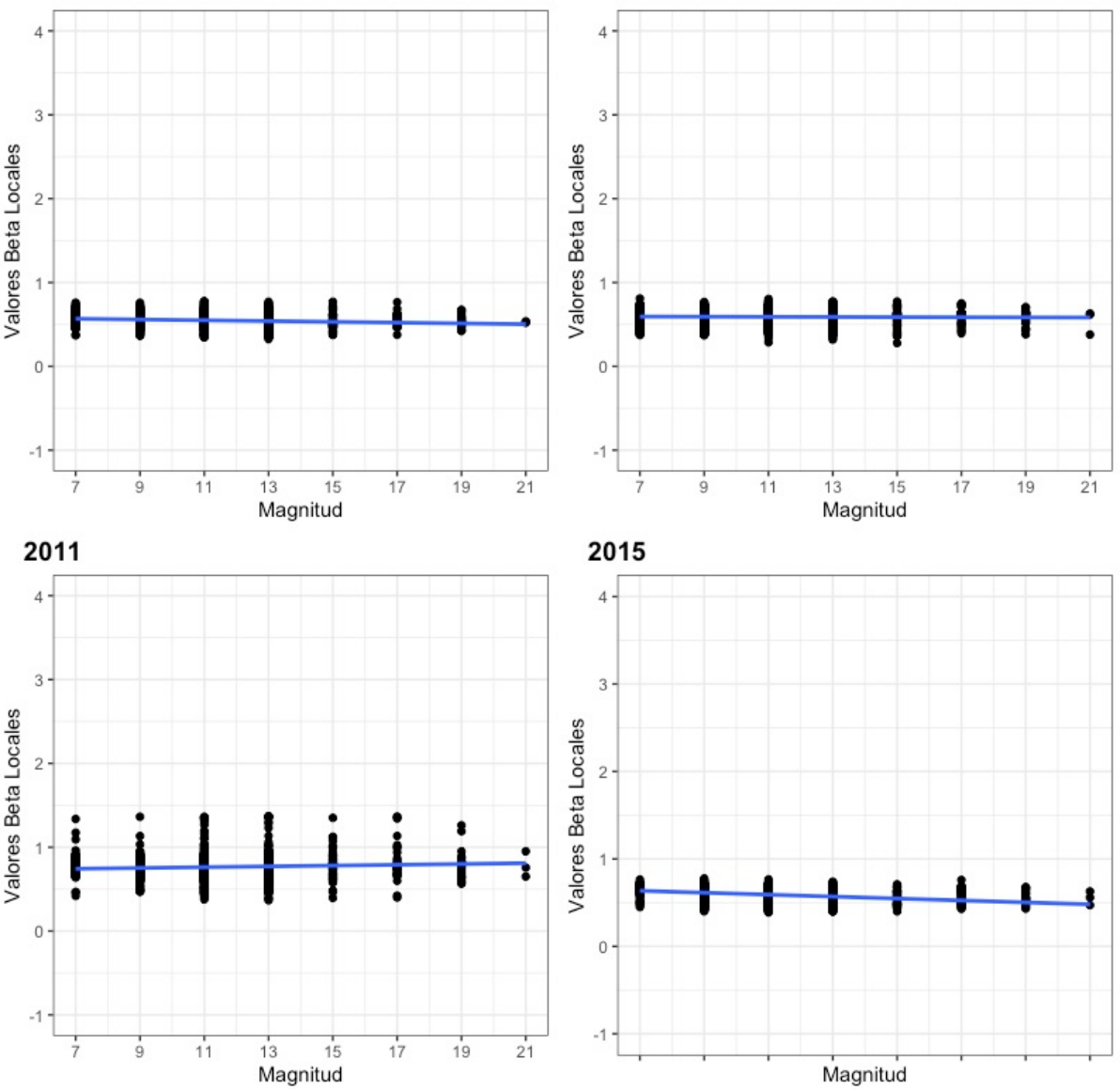
Asimismo, es fundamental remarcar que, antes de 2003, existía una tendencia a que el impacto de la magnitud sobre la competencia personalista fuera mayor (mayores $\beta$ positivos) a medida que $\mathrm{M}$ se incrementaba. Este resultado se produjo sistemáticamente en la mayor parte del país a excepción de un grupo de municipios ubicados en el noreste de Cundinamarca, este de Boyacá y sur de Santander. Mientras tanto, en las elecciones posteriores no solo comenzó a apreciarse un comportamiento espacialmente más errático, sino también, a excepción de 2011, un impacto mucho más moderado de $\boldsymbol{M}$ sobre la competencia intrapartidaria.

Mapa 2. Efectos de $M$ sobre número efectivo de candidatos (GWR)

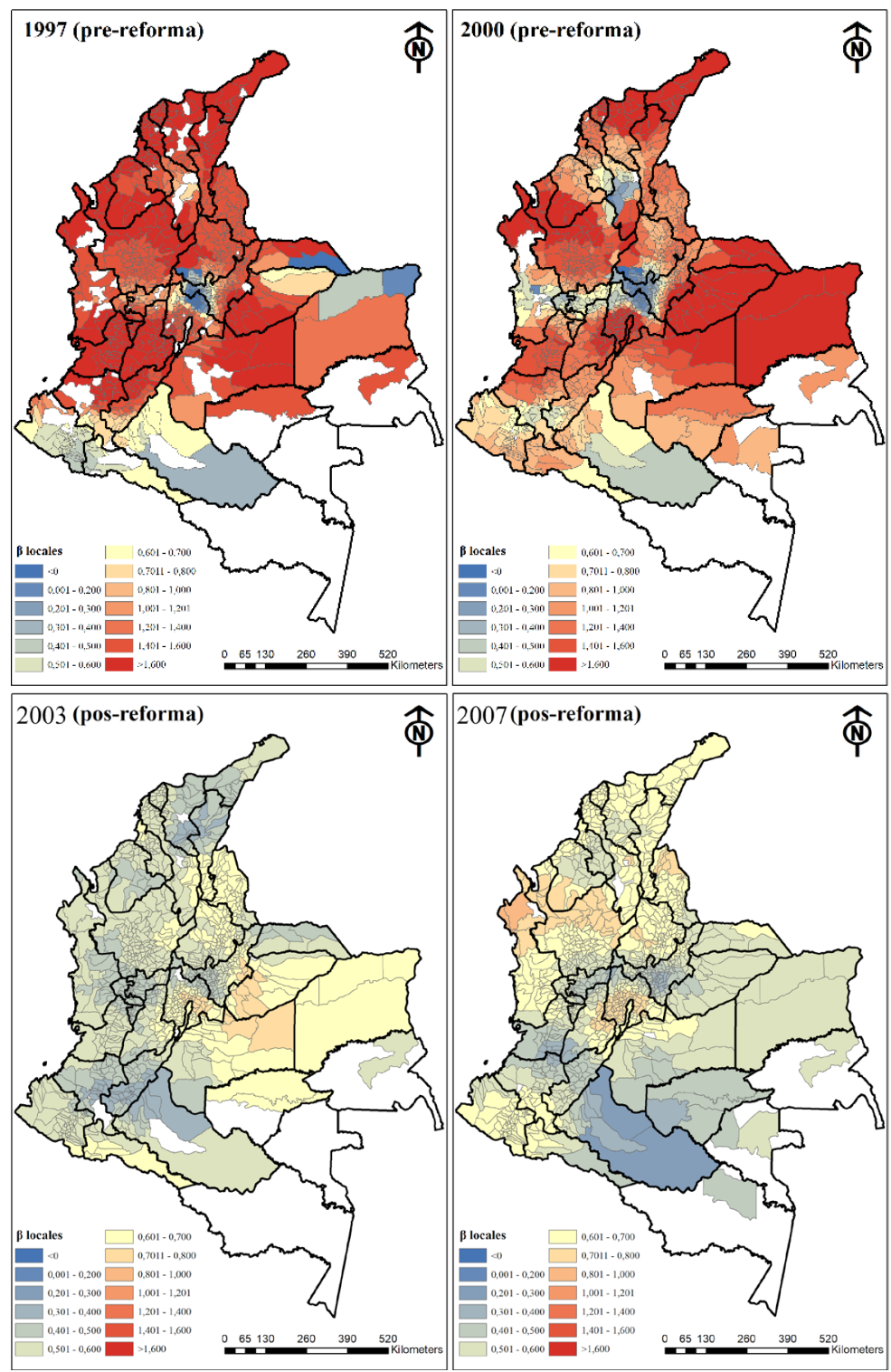




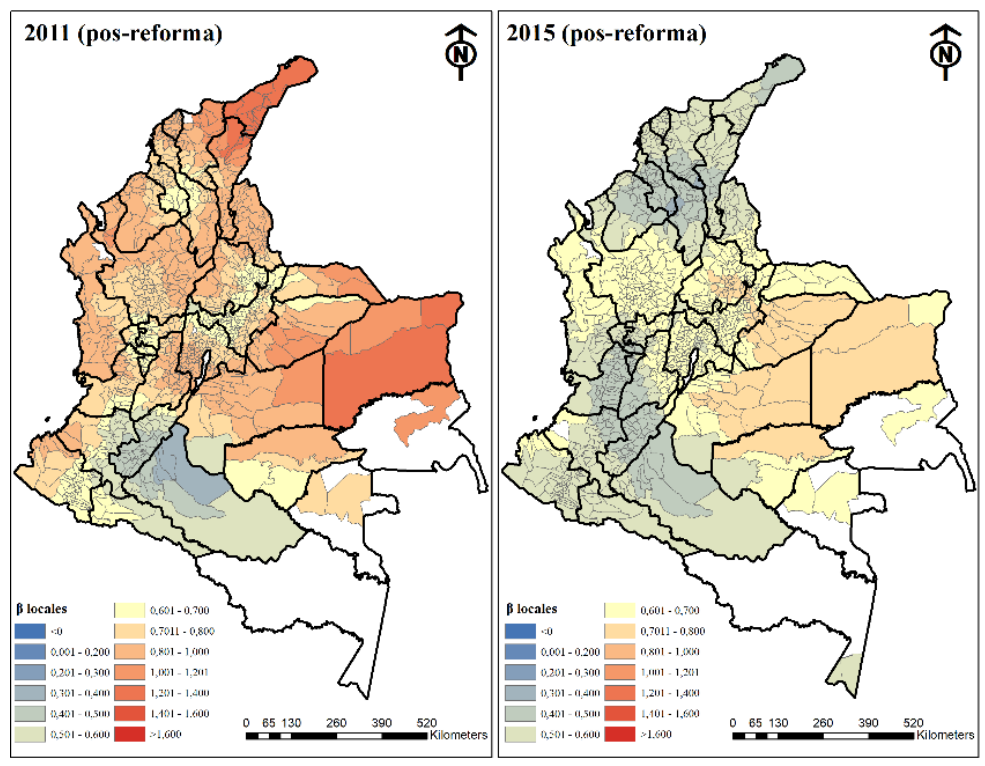

En cuanto a la fragmentación partidaria, puede apreciarse la existencia de una relación positiva entre magnitud y fragmentación (ver Tabla 6). Adicionalmente, como indican la mediana y los cuantiles alto y bajo (los valores máximos y mínimos no son una buena medida porque podrían ser outliers) en la Tabla 6, después de la reforma el impacto estimado de la magnitud es mayor. Sin embargo, al revisar la variación de los $\beta$ de acuerdo con la magnitud se distingue un comportamiento similar antes y después de la reforma (con excepción de las elecciones de 2000) en el que a mayor $\boldsymbol{M}$ menor el valor del coeficiente $\beta$ (ver Gráfico 4 ). Es de suma importancia indicar que el aumento de la dispersión de los datos posterior a 2003 hace que el promedio de los coeficientes sea un indicador menos confiable. Después de las elecciones de ese mismo año, los municipios de magnitud distrital idéntica se han vuelto más disimiles en cuanto al impacto de $\boldsymbol{M}$. 
Tabla 6. Resultados de regresiones geográficamente ponderadas (NEP) por año. ${ }^{11}$

\begin{tabular}{|c|c|c|c|c|c|c|}
\hline & Mínimo & Cuartil bajo & Mediana & Cuartil alto & Máximo & $\begin{array}{c}\text { Diff of } \\
\text { criterion }\end{array}$ \\
\hline \multicolumn{7}{|c|}{1997} \\
\hline NEC & $-0,111037$ & $-0,071881$ & $-0,069278$ & $-0,065222$ & $-0,032495$ & $-10,313107$ \\
\hline Magnitud & 0,071450 & 0,141733 & 0,169297 & 0,192122 & 0,235363 & $-3,120092$ \\
\hline Población & 0 & 0,000001 & 0,000002 & 0,000002 & 0,000011 & $-14,707112$ \\
\hline Constante & $-0,453226$ & 0,775733 & 0,976912 & 1,228336 & 1,846429 & $-18,871083$ \\
\hline \multicolumn{7}{|c|}{2000} \\
\hline NEC & $-0,247228$ & $-0,172323$ & $-0,141232$ & $-0,109472$ & $-0,042318$ & $-19,544423$ \\
\hline Magnitud $^{+}$ & $-0,062340$ & 0,154216 & 0,226168 & 0,295386 & 0,468862 & 0,603945 \\
\hline Población & $-0,000005$ & 0,000001 & 0,000003 & 0,000009 & 0,000052 & $-13,527769$ \\
\hline Constante & $-0,746635$ & 0,737580 & 1,445149 & 2,227626 & 4,055696 & $-65,759762$ \\
\hline \multicolumn{7}{|c|}{2003} \\
\hline NEC & $-1,051532$ & $-0,599633$ & $-0,429635$ & $-0,267989$ & 0,148237 & $-34,925669$ \\
\hline Magnitud & $-0,192222$ & 0,241774 & 0,419755 & 0,583716 & 0,826090 & $-13,213700$ \\
\hline Población & $-0,000032$ & 0,000006 & 0,000018 & 0,000038 & 0,000120 & $-33,834429$ \\
\hline Constante & $-4,702014$ & 1,157572 & 2,151490 & 2,865347 & 5,588669 & $-38,272472$ \\
\hline \multicolumn{7}{|c|}{2007} \\
\hline NEC & $-0,854616$ & $-0,618943$ & $-0,395962$ & $-0,203274$ & 0,439133 & $-45,626109$ \\
\hline Magnitud & 0,117037 & 0,422280 & 0,517250 & 0,689857 & 0,941814 & $-48,999224$ \\
\hline Población & $-0,000005$ & $-0,000001$ & 0,000001 & 0,000004 & 0,000040 & $-51,972081$ \\
\hline Constante & $-1,110895$ & 0,770703 & 0,770704 & 2,137860 & 3,919233 & $-90,217473$ \\
\hline \multicolumn{7}{|c|}{2011} \\
\hline NEC & $-0,938032$ & $-0,307097$ & $-0,229511$ & $-0,145160$ & 0,026692 & $-13,142014$ \\
\hline Magnitud & 0,041797 & 0,323367 & 0,479114 & 0,572567 & 0,837914 & $-14,448303$ \\
\hline Población & $-0,000010$ & 0,000000 & 0,000002 & 0,000008 & 0,000048 & $-11,397567$ \\
\hline Constante & $-0,556552$ & 0,852046 & 1,769472 & 2,822264 & 4,802281 & $-86,400808$ \\
\hline \multicolumn{7}{|c|}{2015} \\
\hline NEC & $-0,856008$ & $-0,556054$ & $-0,369289$ & $-0,201899$ & 0,003460 & $-18,398125$ \\
\hline Magnitud & 0,159205 & 0,426270 & 0,538034 & 0,694579 & 0,988531 & $-9,931179$ \\
\hline Población & $-0,000013$ & 0,000000 & 0,000001 & 0,000002 & 0,000026 & $-25,083117$ \\
\hline Constante & $-0,990214$ & 1,018007 & 1,618518 & 1,970293 & 4,800545 & $-108,539171$ \\
\hline
\end{tabular}

11 Interceptos y variables independientes presentan una variabilidad significativa en su $\beta$ a nivel espacial a excepción de magnitud (2000), indicada por el símbolo t. Si el valor en la última columna ("diff of criterion") es negativo, la variable es espacialmente significativa. No se aprecian problemas de multicolinearidad local (distinguible por los números de condición menores a 30). Esto permitió que el ancho de banda AIC resolviera una cantidad y distancia de vecinos óptima en lugar de utilizar una matriz de pesos predeterminada. 
Gráfico 4. Efectos de la magnitud sobre el número efectivo de partidos según magnitud (GWR)
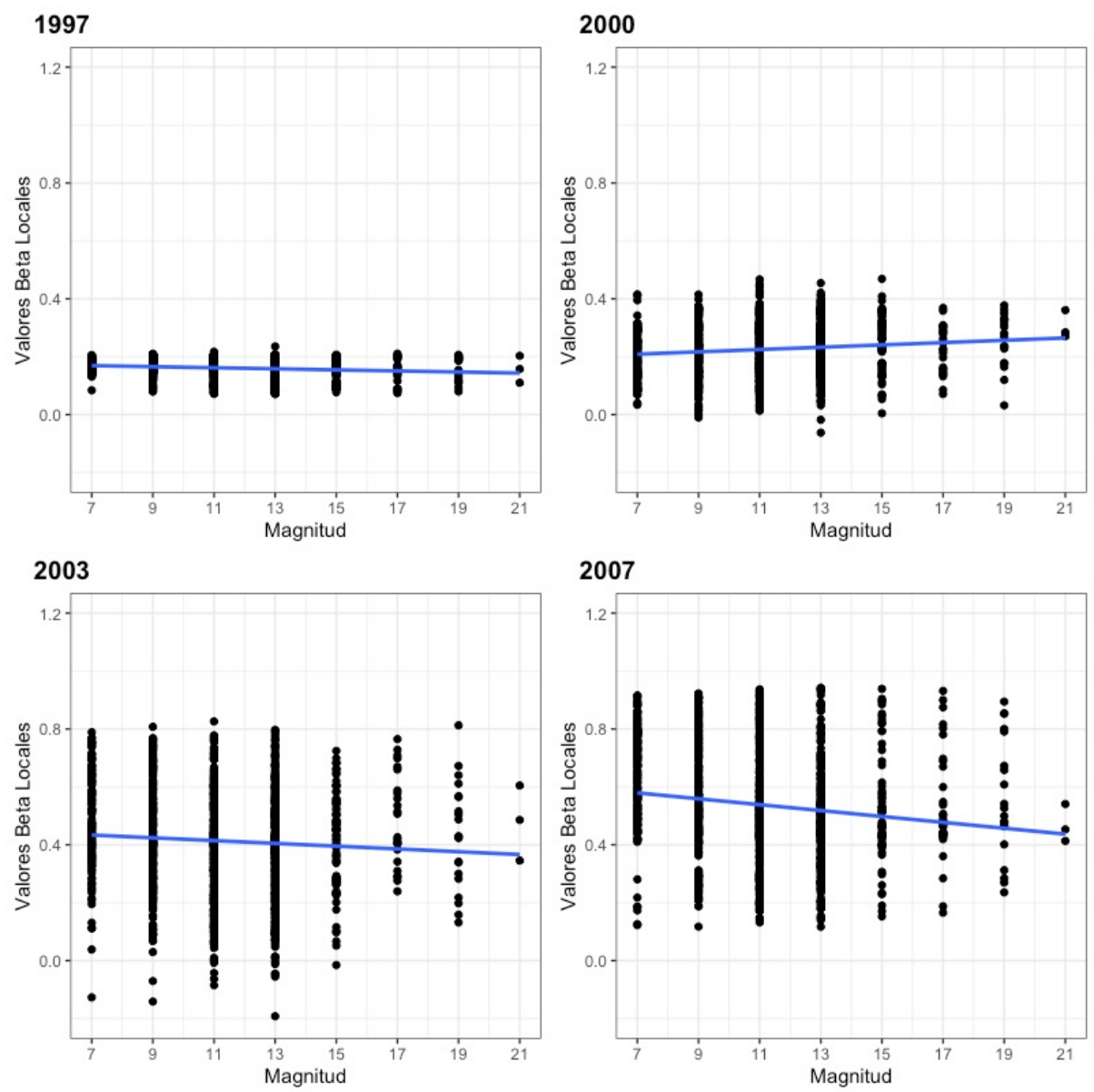

2007
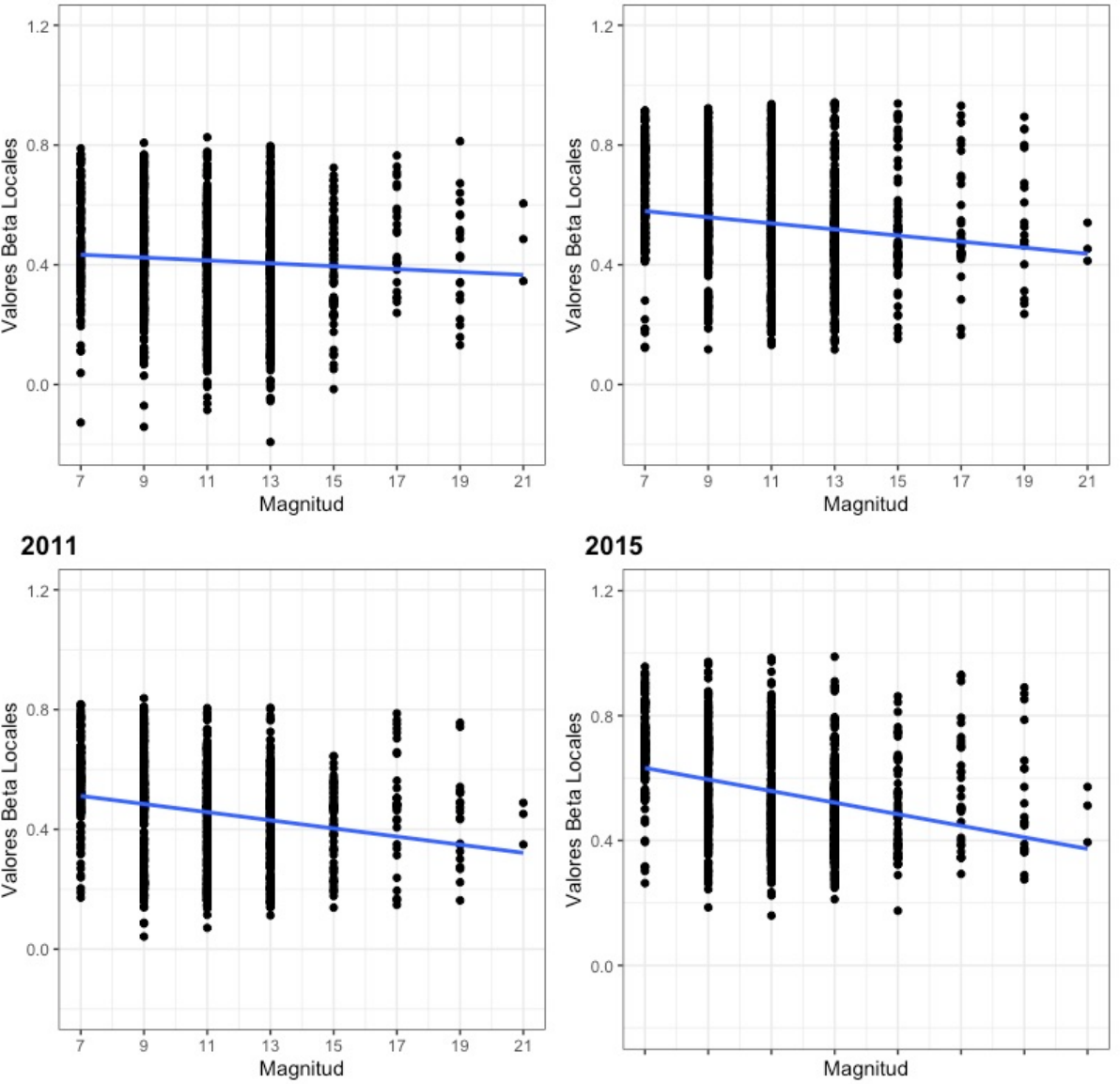

2015

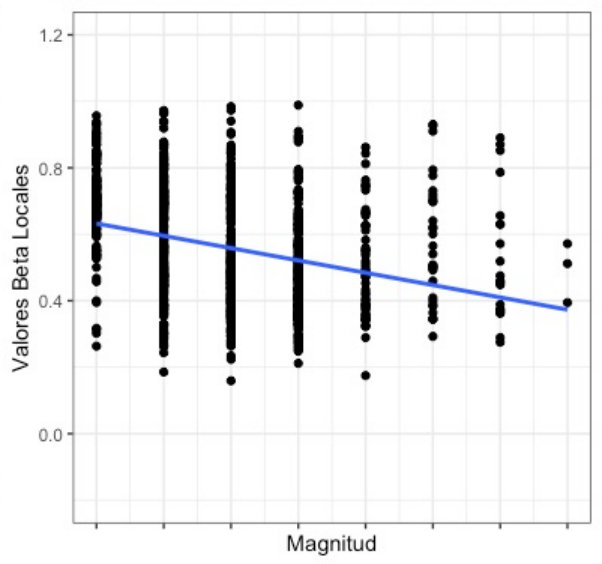


En síntesis, nuestros resultados, tanto de los modelos con efectos fijos como de los geográficamente ponderados, cuestionan la "infalibilidad" de los ejercicios de ingeniería institucional. Si bien esta es una autocrítica realizada desde hace tiempo en los ámbitos académicos, el mismo Sartori (1996) quien acuñara el término resaltó claramente sus límites, no es necesariamente una práctica de muchos de aquellos vinculados a la praxis política.

La reforma de las reglas electorales, que se realizó en Colombia buscando detener la progresiva fragmentación del sistema de partidos y el debilitamiento de los partidos tradicionales observada a nivel nacional, asumió que estos efectos serían similares en otros niveles. Esto ignoró que la atomización del sistema de partidos se concentraba especialmente en el Senado y en los distritos con mayor magnitud en la Cámara. Por consiguiente, el grueso de los concejos municipales exhibió hasta antes de la reforma bajos niveles de fragmentación e incluso la persistencia del bipartidismo tradicional (Hau 2016). El uso de los modelos espaciales contribuyó a mostrar no solamente la existencia de comportamientos heterogéneos desde un punto de vista internivel, sino también las variaciones intranivel apreciables en las divergencias regionales.

También, contrario a las expectativas, en las elecciones de concejos se observa que la fragmentación partidaria y personalista aumenta después de 2003. Si bien no se puede identificar un efecto causal con los métodos empleados, es, por lo menos, evidente que, en este ámbito específico, las reglas empleadas no lograron su objetivo primario. El afán por "racionalizar" el funcionamiento del sistema de partidos solo se materializó en el nivel local a través de una relativa homogenización de las etiquetas partidarias con el nacional. Exigir que la existencia jurídica de un partido estuviera asociada a la superación del umbral legal en el Senado o en la Cámara condujo a que las élites subnacionales utilizaran estas mismas etiquetas partidarias en las diferentes regiones del país manteniendo un alto nivel de autonomía.

De esta forma, los hallazgos producidos en un ámbito mucho menos explorado, como es el municipal, confirman la idea de que la política subnacional no es una función de la nacional. En efecto, aunque indiscutiblemente comparten elementos (apuntalados por arreglos institucionales), pensarla solo como un subconjunto de la primera implica no entender las dinámicas propias que la caracterizan.

Nuestros resultados indican que es importante tener en cuenta que existen comportamientos regionalizados. Esto evidencia que no solo hay una relativa homogeneidad de las conductas de acuerdo con características institucionales relevantes como la magnitud, ya que estas también se cruzan con otras como el territorio. En muchas oportunidades están asociadas a subregiones históricas que difícilmente abracan a la totalidad de este tipo de unidades administrativas, pero que suelen trascender sus fronteras (Sáenz et al. 2020) pasando desapercibidas al revisar los datos agregados. Así, pueden apreciarse comportamientos homogéneos en zonas que pueden exceder a los departamentos como 
los municipios cafeteros, el Urabá, las regiones andinas y pacífico del suroccidente (por separado), los santanderes o la región Caribe.

Esto puede indicar que las élites políticas regionales y locales desarrollan estrategias de adaptación a los cambios institucionales que no solo pueden ser distintas a las de las centrales, sino que pueden llevar a que resultados que, aunque cuantitativamente parecen similares, tienen profundas diferencias cualitativas. En la próxima sección podrá apreciarse cómo patrones similares de fragmentación partidaria y competencia personalista en los municipios de Cali y Palmira ocultan dinámicas opuestas en la competencia política. Estas resultan de las diferentes opciones que tuvieron las élites en los municipios frente al nuevo marco institucional.

\section{VI. ¿TAN SIMILARES, TAN DIFERENTES?}

El análisis más detallado de los casos de Cali y Palmira ilumina aspectos que pasaron desapercibidos en la primera parte del trabajo. Esto de ninguna manera invalida los resultados expuestos anteriormente, pero sí obliga a establecer matices interpretativos que revelan conductas que quedaron ocultas detrás de los datos agregados. Ambos son municipios vecinos que pertenecen a la misma área metropolitana y cuentan con características institucionales similares, en especial por las magnitudes distritales de 19 (Palmira) y 21 (Cali). Asimismo, comparten una realidad política común desde el punto de vista regional, pero con dinámicas propias desde lo local que marcan grandes diferencias.

Como lo muestran los gráficos 5 y 6 , el período previo a la reforma estuvo caracterizado por un denominador común, un sistema partidario contenido desde el punto de vista numérico, bipartidista, $\mathrm{e}$, incluso de partido predominante en el caso de Palmira, pero con un intenso grado de competencia intrapartidaria. De hecho, como puede apreciarse en el Gráfico 5, el número efectivo de candidatos ponderado fue notablemente alto durante esa etapa, alcanzando en Cali (1997) y en Palmira (1997 y 2000) un valor equivalente, inclusive superior a $\boldsymbol{M}$. Tras la reforma se observa en ambos una fuerte disminución de la competencia personalista conforme a los patrones encontrados para municipios de alta magnitud.

Las elecciones se caracterizaron también durante ese período por la presencia de un número notablemente alto de partidos, pero, antes de 2003, el grueso de los votos se concentraba en el PLC y el PCC, siendo las demás fuerzas marginales, ya que no alcanzaban curules en los concejos. Posterior a la reforma, en ambos municipios se incrementó la dispersión de dirigentes de la "diáspora" liberal-conservadora que, sumados a los provenientes de los partidos pequeños, produjeron un notable aumento de la fragmentación partidaria.

En síntesis, el efecto de la reforma estuvo en línea con los principales hallazgos señalados en los apartados anteriores: para los distritos caracterizados por altas magnitudes, la competencia personalista perdió intensidad, lo que aumentó 
Gráfico 5. Número efectivo de candidatos en Cali y Palmira (1997-2015)

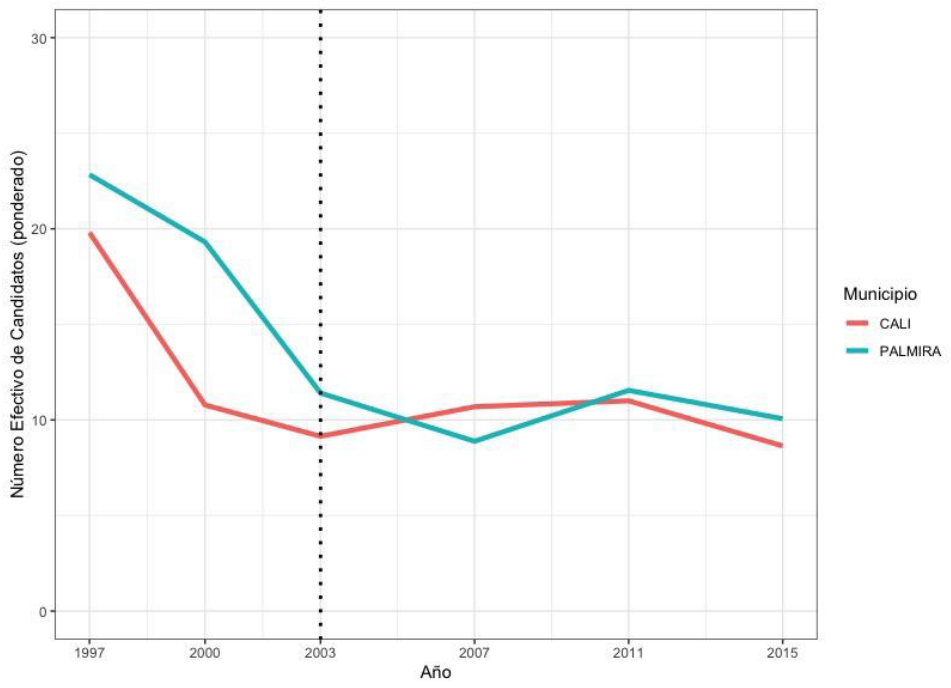

Gráfico 6. Número efectivo de partidos en Cali y Palmira (1997-2015)

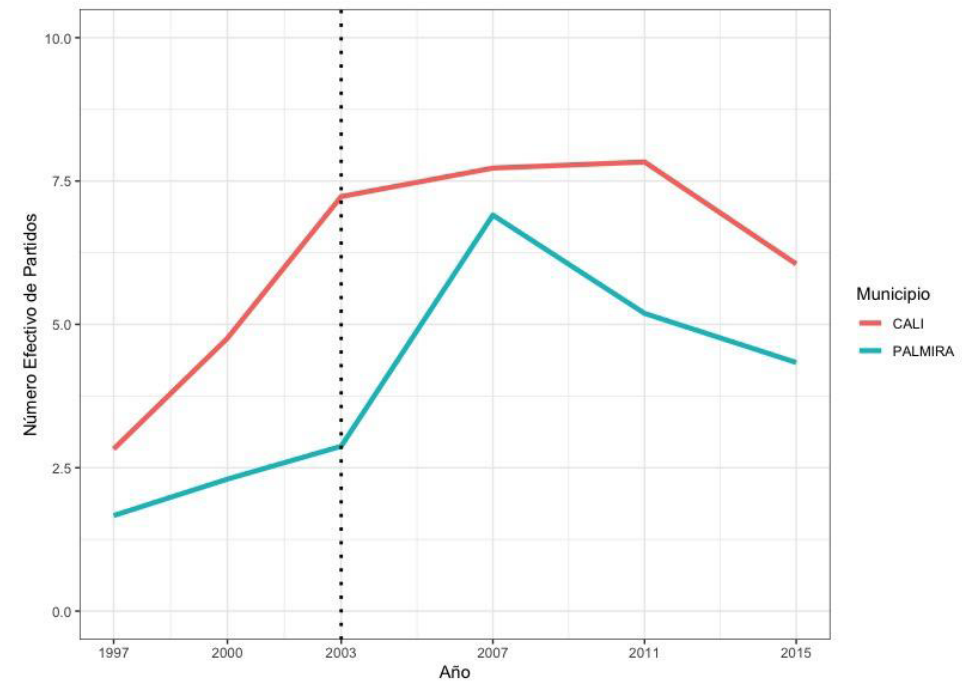

la fragmentación partidaria. También, como se planteó, los resultados tienden a ser homogéneos entre municipios con características similares, más cuando estos pertenecen a una misma región.

De todas maneras, y a pesar de las similitudes observables en las trayectorias de la competencia personalista y la fragmentación partidaria de Cali y Palmira, 
la trastienda de los procesos políticos revela mucho sobre cómo las élites pueden reaccionar de forma variada, incluso en escenarios institucionales similares. Así, aun cuando ambas exhiban comportamientos alineados con los resultados generales, en Palmira esto sucede en un contexto en el que una máquina política alcanza la hegemonía en el municipio, mientras que en Cali ocurre a través de múltiples maquinarias competitivas.

Para el caso de Cali, el cambio institucional se produjo en un escenario caracterizado por una dirigencia política atomizada. De hecho, no existe en la ciudad ninguna gran máquina política capaz de dominar autónomamente las elecciones de concejo o de alcaldía. Una parte significativa de los actores más relevantes provenían del PLC o PCC y encontraron en las nuevas en etiquetas partidarias surgidas en el período 2002-2010 un espacio para reacomodarse estratégicamente, logrando, con caudales electorales relativamente modestos, maximizar sus oportunidades de ser electos. En esencia, se aproximaron a una franquicia partidaria para cumplir con requisitos legales, manteniendo su autonomía frente a estructuras partidarias, compitiendo a través de su músculo electoral propio o mediante organizaciones políticas (máquinas) personalistas.

Al no existir una fuerza política dominante en la ciudad, los principales grupos locales forman coaliciones para ganar las elecciones a la alcaldía, pero estas no se construyen a partir de los partidos, sino de la articulación de las máquinas conformadas en torno a algún líder. De este modo, cada partido, en cabeza de alguno de sus dirigentes locales, termina respaldando simultáneamente a más de uno de los principales candidatos a ocupar la jefatura del gobierno municipal, produciéndose una red de apoyos anidados que difiere de las etiquetas formales. Incluso, algunas de las principales maquinarias, como la de "Nueva Generación", hacen lo mismo con más de un candidato, garantizándose así cuotas de patronazgo independientemente del ganador (Milanese y Barrero 2016). En pocas palabras, la fragmentación partidaria en Cali refleja la competencia entre grupos políticos por lograr algún espacio en el poder municipal.

En cambio, Palmira se ha caracterizado, por lo menos desde 2007, por un creciente control hegemónico de una máquina política: el caicedismo. En ella se agrupan antiguos políticos liberales provenientes del becerrismo, facción del PLC que contaba con varios alcaldes en el departamento del Valle del Cauca (Sáenz 2010; Serrano 2020). Frente a incentivos institucionales que producen proporcionalidad en la representación de las fuerzas políticas, el caicedismo no optó por crear un partido y centralizar en él la participación electoral de todos sus dirigentes. Más bien, entendió que su predominio dependía de la cooptación de múltiples opciones partidarias y grupos sociales, y aunque su eje se centra actualmente en el Partido Social de la Unidad Nacional (PSUN) ${ }^{12}$ está inserto en diversas etiquetas partidarias dentro del municipio, logrando sos- 
tener su predominio en el concejo, que creció de un $25 \%$ de los asientos en su primera elección en 2007 hasta la mayoría absoluta que mantiene desde 2011.

Este escenario termina produciendo una situación paradójica en la que, pese a la alta fragmentación del sistema de partidos, existe un actor predominante que alcanza autónomamente mayorías "legislativas", es más, el movimiento funciona como un aglutinador de células de base que se disputan tanto liderazgos como votos sin distinciones territoriales en una suerte de mercado libre electoral, pero con liderazgos bien definidos especialmente en la cúpula (Serrano 2020). La fragmentación partidaria en Palmira refleja la manera en que una máquina política hegemónica opera electoralmente en el contexto de las reglas establecidas en 2003 y no en una competencia entre diferentes fuerzas políticas.

Finalmente, vale aclarar que, más que interpretar las razones que explican la imposibilidad de construir una máquina política predominante en Cali y su existencia en Palmira, ${ }^{13}$ la presentación de estos casos pretende mostrar que, incluso cuando se realiza análisis cuantitativo subnacional, es primordial acompañarlo por conocimiento contextual. En estos casos puede apreciarse que aunque las trayectorias generales de la fragmentación partidaria y competencia personalista antes y después de la reforma son muy similares, la existencia de una dirigencia política más concentrada en Palmira permitió el ascenso de una máquina predominante que navegó las reglas electorales después de 2003, controlando o cooptando varias siglas partidarias, mientras que en Cali la atomización de las dirigencias (máquinas) políticas condujo también a la fragmentación partidaria. En ambas ciudades, el resultado es nominalmente el mismo. Sin embargo, las dinámicas de competencia electoral en cada de una de ellas no lo son.

\section{VII.CONSIDERACIONES FINALES}

Como quedó demostrado a lo largo del trabajo para el caso colombiano, la política electoral subnacional no es un reflejo de lo que sucede en el ámbito nacional. Estas diferencias hacen que los mismos arreglos institucionales produzcan efectos completamente distintos en cada uno de ellos, situación particularmente visible en el caso de la Reforma Política de 2003. Si bien esta alcanzó los resultados deseados: contener la fragmentación partidaria y, con menor éxito, la intrapartidaria personalista para el caso del Senado, estos difirieron notablemente, en promedio, en los concejos municipales.

13 Si bien, como se mencionó, no se pretende encontrar las causas de la convergencia de los resultados alcanzados por distintas vías, intuitivamente las diferencias entre las dirigencias políticas podrían residir en la brecha poblacional que exhiben ambos municipios (alrededor de 2.5 millones Cali y 350 mil Palmira). No obstante, como observa Serrano (2020), existen municipios del mismo tamaño que Palmira que cuentan con dirigencias atomizadas y ciudades grandes como Barranquilla que tienen máquinas políticas crecientemente hegemónicas. 
Utilizando modelos de efectos fijos y geográficamente ponderados, pudo observarse que el cambio institucional produjo, incluso, resultados inversos a los propuestos por los reformadores: mayor fragmentación partidaria y competencia personalista.

Adicionalmente, la revisión de dos casos similares (Cali y Palmira) ofrece valiosa información que muestra cómo pueden alcanzarse resultados nominalmente similares (altos niveles de fragmentación partidaria), pero que ocultan dinámicas de competencia política muy diferentes. La fragmentación partidaria puede indicar, al mismo tiempo, la competencia entre una dirigencia política atomizada (Cali) o resultar de una efectiva estrategia de control por parte de una máquina política hegemónica (Palmira).

Los aspectos ligeramente señalados resaltan la importancia del uso de diseños de investigación subnacional que, como señalan Giraudy et al. (2019), permiten evitar análisis imprecisos "contaminados" por un sesgo nacional y, por lo tanto, sortear problemas como el theory stretching o la aplicación irreflexiva de teorías sin considerar el nivel de análisis para el que fueron pensadas y aquel para el que se las piensan emplear.

Adicionalmente, el artículo muestra la importancia del uso de múltiples métodos en el marco de un análisis subnacional. En este caso, la combinación de métodos permitió que la evaluación de los efectos promedio de la reforma fuera complementada por un análisis espacial que mostrara diferencias entre municipios y regiones. A su vez, los casos de estudio son necesarios para exponer cómo, detrás de las similitudes observadas en los indicadores de fragmentación partidaria y competencia personalista, existen fuertes divergencias en las dinámicas de competencia política. Aunque usualmente utilizadas para fortalecer estrategias de inferencia causal (Seawright 2016; Goertz 2017), el uso de múltiples métodos también permite mejorar la interpretación de los datos y tener descripciones más robustas de procesos políticos.

\section{REFERENCIAS}

Abadía, Adolfo. 2016. "Elecciones a las gobernaciones departamentales de Colombia: la fragmentación en este subsistema de partidos." Revista Brasileira de Direito Eleitoral e Ciência Política 5(1): 7-38.

Albarracín, Juan, Laura Gamboa y Scott Mainwaring. 2018. "Deinstitutionalization Without Collapse: Colombia's Party System." En Party Systems in Latin America. Institutionalization, Decay and Collapse, editado por Scott Mainwaring. New York: Cambridge University Press, 227-254.

Albarracín, Juan. 2020. "Cambios y continuidades en las elecciones subnacionales de la región Pacífico (1997-2019)." En Elecciones subnacionales 2019. Hacia una redefinición de los partidos y de sus campañas electorales, editado por Fredy Barrero y Eugénie Richard. Bogotá: KAS, 479-509.

Batlle, Margarita y José Ricardo Puyana. 2013. "Reformas políticas y partidos en Colombia: cuando el cambio es la regla." Politai 4(2): 73-88. 
Batlle, Margarita, Carlos Andrés Hoyos y Laura Wills-Otero. 2020. "Electoral Competition at the Subnational Level. Emeralds and Politics in Colombia, 1997-2015." Colombia Internacional 103: 57-83.

Bedoya, John Fredy y Juan Carlos Arenas. 2015. “Incidencia de los cambios en las reglas de la competencia electoral sobre nacionalización del sistema de partidos: las estrategias de los actores políticos en Antioquia, 1997-2011." Colombia Internacional 85: 81-110.

Botero, Felipe y Juan Carlos Rodríguez Raga, J. 2008. Grande no es sinónimo de fuerte. Bogotá: PNUD/IDEA.

Botero, Felipe y David Alvira. 2011. "Fulano de tal va por su aval. Desconexión entre los niveles nacionales y locales de los partidos políticos en Colombia." En Política y territorio: Análisis de las elecciones subnacionales en Colombia, 2011, editado por Laura Wills y Margarita Batlle, Bogotá: PNUD, 131-161.

Botero, Felipe, Rodrigo Losada y Laura Wills. 2016. "Sistema de partidos en Colombia 19742014: ¿la evolución hacia el multipartidismo?" En Los sistemas de partidos en América Latina 1978-2015. Tomo 2. Cono Sur y Países Andinos, editado por Flavia Freidenberg. Ciudad de México: UNAM, 131-161.

Carey, John y Matthew Shugart. 1995. "Incentives to Cultivate a Personal Vote: A Rank Ordering of Electoral Formulas." Electoral Studies 14(4): 417-439.

CINEP. 1998. Colombia País de regiones. Tomo I. Bogotá: CINEP.

Clavijo García, Camilo. 2007. "La región en la irresuelta reordenación del territorio nacional: de lo económico y funsional a la construcción social del Estado nacional." Bitácora 11(1): 240-247.

Cox, Gary y Matthew Shugart. 1995. "In the absence of vote pooling: Nomination and vote allocation errors in Colombia." Electoral Studies 14(4):441-460.

Cox, Gary. 1997. Making Votes Count. Cambridge: Cambridge University Press.

Crisp, Brian, María C. Escobar-Lemon, Bradford Jones, Mark Jones y Michelle Taylor-Robinson. 2004. "Vote-Seeking Incentives and Legislative Representation in Six Presidential Democracies." The Journal of Politics 66(3): 823-846.

Dargent, Eduardo y Paula Muñoz. 2011. "Democracy Against Parties? Party System Deinstitutionalization in Colombia." Journal of Politics in Latin America 3(2): 51-72.

De Smith, Michael, Michael Goodchild y Paul Longley. 2018. Geospatial Analysis. A Comprehensive Guide to Principles Techniques and Software Tools. Winchelsea: The Winchelsea Press.

Duverger, Maurice. 1954. Political Parties. New York: Wiley.

Fotheringham, Stewart, Chris Brunsdon y Martin Charlton. 2002. Geographically Weighted Regression. Sussex: Wiley.

Gallagher, Michael y Paul Mitchel. 2005. The Politics of Electoral Systems. Oxford: Oxford University Press.

Gamboa, Laura. 2012. "Campaigning With Empty Pockets: Why the Liberal Party Wins Regional Elections in Colombia." Ponencia presentada en XXX Congress of the Latin American Studies Association, San Francisco, 23-26 de mayo.

García, Miguel. 2006. "La reforma electoral y su impacto en las elecciones locales de 2003. Un análisis de las elecciones del Concejo de Bogotá." En La Reforma Política de 2003 ¿La salvación de los partidos políticos colombianos?, editado por Gary Hoskin y Miguel García. Bogotá: Ediciones Uniandes, 109-136.

Giraudy, Agustina, Eduardo Moncada y Richard Snyder. 2019. "Subnational Research in Comparative Politics." En Inside Countries. Subnational Research in Comparative Politics, editado por Agustina Giraudy, Eduardo Moncada y Richard Snyder, Cambridge: Cambridge University Press, 2-54.

Goertz, Gary. 2017. Multimethod Research, Causal Mechanisms, and Case Studies: An Integrated Approach. Princeton: Princeton University Press.

Gutiérrez Sanín, Francisco. 2001. “Se ha abierto el sistema político colombiano?” América Latina Hoy 27: 189-215. 
Gutiérrez Sanín, Francisco. 2007. ¿Lo que el viento se llevó?: los partidos políticos y la democracia en Colombia, 1958-2002. Bogotá: Norma.

Harbers, Imke y Matthew Ingram. 2019. "Politics in Space." En Inside Countries. Subnational Research in Comparative Politics, editado por Agustina Giraudy, Eduardo Moncada y Richard Snyder. Cambridge: Cambridge University Press, 57-91.

Hau, Alexandra. 2016. "Persistencia del bipartidismo en el Valle del Cauca, 1992 - 2015." Politai 7(13): 15-33.

Hoskin, Gary y Miguel García. 2006. La Reforma Política de 2003 ¿La salvación de los partidos politicos colombianos? Bogotá: Ediciones Uniandes.

Hoyos, Diana. 2007. "La reforma Política de 2003 y su impacto sobre el sistema de partidos: Análisis de las elecciones a Congreso." En Entre la persistencia y el cambio: Reconfiguración del escenario partidista y electoral en Colombia, editado por Diana Hoyos. Bogotá: Universidad del Rosario, 174-215.

Katz, Richard. 1986. "Intraparty Preference Voting." En Electoral Laws and Their Political Consequences, editado por Arend Lijphart y Bernard Grofman. New York: Agathon Press, 85-103.

Laakso, Markku y Rein Taagepera. 1979. "Effective Number of Parties. A Measure With Application to West Europe." Comparative Political Studies 12(1): 3-27.

Leal Buitrago, Francisco y Andrés Dávila. 1990. Clientelismo: el sistema político y su expresión regional. Bogotá: Universidad de Los Andes.

Milanese, Juan Pablo y Luis Jaramillo. 2015. "Impacto de los factores institucionales del sistema electoral en la fragmentación partidaria. Un análisis de las elecciones para concejos municipales en el Valle del Cauca (1997-2011)." Colombia Internacional 84: 43-70.

Milanese, Juan Pablo y Fredy Barrero. 2016. "Selección de Candidatos en Escenarios de Atomización Dirigencial. Análisis de los Casos de Cali y El Valle del Cauca, Elecciones Locales y Regionales 2015." Análisis Político 88: 69-89.

Milanese, Juan Pablo y Margarita Batlle. 2018. "Fragmentación y factores institucionales: un análisis de los sistemas de partidos de Valle del Cauca, Cauca y Nariño." En Polarización y posconflicto: Las elecciones nacionales y locales en Colombia, 2014-201, editado por Felipe Botero, Miguel García y Laura Wills. Bogotá: Universidad de los Andes, 269-290.

Milanese, Juan Pablo y Juan Albarracín. 2020. “Estrategias geo-espaciales para la medición de la congruencia inter-nivel del sistema de partidos. Análisis del caso colombiano 19822018." Ponencia presentada en XXXVIII International Congress of the Latin American Studies Association, virtual, 13-16 de mayo.

Milanese, Juan Pablo, Juan Albarracín y Luis Eduardo Jaramillo. 2014. "Patrones de competencia intrapartidaria en los partidos colombianos. Análisis del caso de la región suroccidental." Ponencia presentada en el XXXII International Congress of the Latin American Studies Association, Chicago, 21-24 de mayo.

Moreno, Érika y María Escobar-Lemmon. 2008. “Mejor Solo Que Mal Acompañado: Political Entrepreneurs in Colombia." En Pathways to Power: Political Recruitment and Candidate Selection in Latin America, editado por Peter Siavelis y Scott Morgenstern. University Park: Penn State Press, 119-141.

Pachón, Mónica. 2004. “Congreso y partidos políticos en Colombia: una mirada a las instituciones." En Fortalezas de Colombia, editado por Fernando Cepeda. Bogotá: Ulloa Editorial, 87-104.

Pachón, Mónica y Matthew Shugart. 2010. "Electoral Reform and the Mirror Image of Inter-Party and Intra-Party Competition: The Adoption of Party Lists in Colombia." Electoral Studies 29(4): 648-660.

Pachón, Mónica y Fabio Sánchez. 2014. Base de Datos Electorales del CEDE. Bogotá: Universidad de Los Andes.

Pino, Juan Federico. 2020. “Trayectorias de Desarrollo de la Competitividad Electoral Subnacional en las Alcaldías Colombianas: 1988-2015." Dados 63(3): 1-43. 
Pizarro, Eduardo. 2002. "La atomización partidista en Colombia: el fenómeno de las microempresas electorales." En Degradación o cambio: evolución del sistema político colombiano, editado por Francisco Gutiérrez Sanín. Bogotá: Norma, 357-395

Rodríguez Raga, Juan Carlos. 2006. “Ordenando el caos: Elecciones legislativas y reforma electoral en Colombia." Revista de Ciencia Política 26(1): 138-151.

Sáenz, José. 2010. Élite política y construcciones de ciudad. Cali: Universidad Icesi.

Sáenz, José, Enrique Rodríguez Caporalli y Juan José Fernández. 2020. Ciudades, subregiones y redes en el suroccidente colombiano: infraestructura, migración, mercado y formas asociativa. Cali: Universidad Icesi.

Sartori, Giovanni. 1996. "Límites de la ingeniería constitucional." Justicia Electoral 8: 45-51.

Seawright, Jason. 2016. Multi-Method Social Science: Combining Qualitative and Quantitative Tools. New York: Cambridge University Press.

Serrano, Camilo. 2020. "Son gente como yo. Brókeres y construcción de maquinaria política en la ciudad de Palmira, Valle del Cauca, Colombia (2008-2019)." Estudios Políticos 59: 227-251.

Shugart, Matthew. 2005. “Comparative Electoral Systems Research: The Maturation of a Field and New Challenges Ahead." En The Politics of Electoral Systems, editado por Michael Gallagher y Paul Mitchel. Oxford: Oxford University Press, 25-56.

Shugart, Matthew, Érika Moreno y Luis Fajardo. 2007. “Deepening Democracy Through Renovating Political Practices: The Struggle for Electoral Reform in Colombia." En Peace, Democracy, and Human Rights in Colombia, editado por Christopher Welna y Gustavo Gallón. Notre Dame: University of Notre Dame Press, 202-266.

Shugart, Matthew, Melody Valdini y Kati Suominen. 2005. “Looking for Locals: Voter Information Demands and Personal Vote-Earning Attributes of Legislators Under Proportional Representation." American Journal of Political Science 49(2): 437-449.

Snyder, Richard. 2001. "Scaling Down: The Subnational Comparative Method." Studies in Comparative International Development 36: 93-110.

Suarez-Cao, Julieta, Margarita Batlle y Laura Wills. 2017. "El auge de los estudios sobre la política subnacional latinoamericana." Colombia Internacional 90: 15-34.

Wills, Laura. 2009. "El sistema político colombiano: las reformas electorales de 1991 y 2003 y la capacidad de adaptación de los partidos." En ¿Juntos pero no revueltos? Partidos, elecciones y campañas en las elecciones legislativas de 2006 en Colombia, editado por Felipe Botero. Bogotá: Uniandes, 11-47.

Zorn, Christopher. 2001. "Generalized Estimating Equation Models for Correlated Data: A Review With Applications." American Journal of Political Science 45(2): 470-490.

Recibido: 4 de agosto de 2020

Aceptado: 5 de febrero de 2021

Juan Albarracín. B.A. en Ciéncia Política y M.A en Política Comparada de la Eberhard-Karls Universität Tübingen. M.A y PhD en Ciencia Política de la University of Notre Dame. Profesor asistente del Departamento de Estudios Políticos y director del Programa de Ciencia de la Universidad Icesi, Cali, Colombia. Correo electrónico: jgalbarracin@icesi.edu.co

Juan Pablo Milanese. Licenciado en Ciencia Política de la Universidad de Buenos Aires (UBA). Magíster en Relaciones Internacionales de la Universidad de Bolonia y en Ciencias y Sistemas de la Información Geográfica de la Universidad de Salzburgo. Doctor en Ciencias Políticas y Sociales de la Universidad de Bolonia. Profesor titular del Departamento de Estudios Políticos de la Universidad Icesi. Investigador Sénior, escalafón del Departamento Administrativo de Ciencia, Tecnología e Innovación (COLCIENCIAS). Correo electrónico: jmilanese@icesi.edu.co 
